\title{
mTORC1-independent autophagy regulates receptor tyrosine kinase phosphorylation in colorectal cancer cells via an mTORC2-mediated mechanism
}

\author{
Aikaterini Lampada ${ }^{1,2}$, James O'Prey ${ }^{3}$, Gyorgy Szabadkai ${ }^{4}$, Kevin M Ryan ${ }^{3}$, Daniel Hochhauser ${ }^{\star 2,5}$ and Paolo Salomoni ${ }^{\star 1,5}$
}

The intracellular autophagic degradative pathway can have a tumour suppressive or tumour-promoting role depending on the stage of tumour development. Upon starvation or targeting of oncogenic receptor tyrosine kinases (RTKs), autophagy is activated owing to the inhibition of PI3K/AKT/mTORC1 signalling pathway and promotes survival, suggesting that autophagy is a relevant therapeutic target in these settings. However, the role of autophagy in cancer cells where the PI3K/AKT/mTORC1 pathway is constitutively active remains partially understood. Here we report a role for mTORC1-independent basal autophagy in regulation of RTK activation and cell migration in colorectal cancer (CRC) cells. PI3K and RAS-mutant CRC cells display basal autophagy levels despite constitutive mTORC1 signalling, but fail to increase autophagic flux upon RTK inhibition. Inhibition of basal autophagy via knockdown of ATG7 or ATG5 leads to decreased phosphorylation of several RTKs, in particular c-MET. Internalised c-MET colocalised with LAMP1-negative, LC3-positive vesicles. Finally, autophagy regulates c-MET phosphorylation via an mTORC2dependent mechanism. Overall, our findings reveal a previously unappreciated role of autophagy and mTORC2 in regulation of oncogenic RTK activation, with implications for understanding of cancer cell signalling.

Cell Death and Differentiation (2017) 24, 1045-1062; doi:10.1038/cdd.2017.41; published online 5 May 2017

Macroautophagy (hereafter referred to as autophagy) is a conserved and tightly regulated catabolic self-renewal pathway helping cells maintain their homoeostasis and overcome stress stimuli. Autophagy mediates degradation of cytoplasmic long-lived proteins and organelles into lysosomes via their previous engulfment into cytoplasmic double membrane vacuoles, called autophagosomes. ${ }^{1}$ Autophagy is present at basal levels (basal autophagy) in most cells and tissues and functions as a quality control mechanism. ${ }^{2}$ Upon stress, such as nutrient/growth factor deprivation or cancer treatment, autophagy is upregulated providing nutrient and energy precursors to enable survival. $^{3}$ The PI3K/AKT/mTORC1 pathway is a master negative regulator of autophagy via controlling the initiation of this catabolic process. ${ }^{4-6}$ Aside from regulating autophagosome initiation, $\mathrm{mTORC} 1$ has been suggested to control autophagosome maturation in nutrientreplete conditions. ${ }^{7}$ However, autophagy can also be regulated via mTOR-independent mechanisms. ${ }^{8-10}$

In the context of cancer initiation and progression, autophagy is considered to have an important, albeit complex, role. ${ }^{5}$ Autophagy holds a tumour suppressive function during early tumourigenesis, ${ }^{11-16}$ whereas it can also sustain cancer progression. ${ }^{17-25}$ Increased levels of basal autophagy have been found in a variety of cancer tissues including colorectal cancer (CRC), where autophagy supports tumour growth and increases tumour aggressiveness. ${ }^{20}$
Autophagy is inhibited by oncogenic tyrosine kinases (OncTKs) and receptor tyrosine kinases (RTKs) via activation of the PI3K/AKT/mTORC1 and RAS/MAPK signalling. ${ }^{5}$ Work from our group and others has shown that induction of autophagy upon pharmacological targeting of OncTKs/RTKs promotes survival. In turn, pharmacological inhibition of autophagy potentiates OncTK/RTK-targeted therapy. 4,5,17 In particular, autophagy has been placed downstream of two cancer-related RTKs, the epidermal growth factor receptor (EGFR) $)^{8,9,26-32}$ and the hepatocyte growth factor receptor, $\mathrm{C}-M E T^{33}$ EGFR regulates autophagy either directly ${ }^{8,9}$ or indirectly through its downstream effectors. Both EGFR and c-MET can have tumour-promoting roles in CRC. ${ }^{34,35}$ Although autophagy acts as a pro-survival mechanism upon nutrient deprivation in $\mathrm{CRC},{ }^{36}$ it remains unclear whether its inhibition could potentiate RTK-targeted therapy.

Here, we provide insights into the relationship between autophagy and RTK activation in CRC cells. In most CRC cell lines analysed, autophagy is not induced upon RTK inhibition owing to constitutive PI3K/AKT/mTORC1 signalling. Interestingly, CRC cells display detectable basal autophagy despite RAS and PI3K activation. Unexpectedly, inhibition of basal autophagy affects tyrosine phosphorylation of several RTKs, in particular c-MET. Internalised c-MET colocalised with LAMP1-negative, LC3-positive vesicles. The effect on c-MET phosphorylation upon autophagy inhibition is functionally

\footnotetext{
${ }^{1}$ UCL Cancer Institute, Department of Cancer Biology, London, UK; ${ }^{2}$ UCL Cancer Institute, Department of Oncology, London, UK; ${ }^{3}$ Beatson Institute, Glasgow, UK and ${ }^{4}$ Department of Cell and Developmental Biology, Consortium for Mitochondrial Research, UCL, London, UK

${ }^{*}$ Corresponding author: D Hochhauser, UCL Cancer Institute, Department of Oncology, Paul O'Gorman Building, 72 Huntley Street, London, WC1E 6DD, UK. Tel: +44 207679 6006; Fax: +44 207-6794925; E-mail: d.hochhauser@ucl.ac.uk

or P Salomoni, UCL Cancer Institute, Department of Cancer Biology, Paul O'Gorman Building, 72 Huntley Street, London, WC1E 6DD, UK. Tel: +44 20 7679 0728 ; Fax: +44 207-6796643; E-mail: p.salomoni@ucl.ac.uk

${ }^{5}$ These authors contributed equally to this work.

Received 15.7.16; revised 16.2.17; accepted 20.2.17; Edited by E Baehrecke; published online 05.5.2017
} 
linked to decreased mTORC2 signalling. Overall, our findings suggest a previously unreported function of basal autophagy in the regulation of $\mathrm{mTORC2}$ and RTK activation, with implications for our understanding of the role of autophagy in cancer cell signalling.

\section{Results}

RTK inhibition fails to induce autophagy in CRC cells owing to constitutive mTORC1 signalling. Work from our laboratory and others has shown that autophagy is induced upon pharmacological targeting of OncTKs/RTKs in cancer cells owing to inhibition of the PI3K/AKT/mTORC1 pathway, promoting survival. ${ }^{17,29,30,32}$ We set out to investigate the RTK-autophagy pathway in CRC, where RTK signalling is implicated in tumour development and is targeted clinically. Specifically, monoclonal antibodies targeting EGFR have been employed in CRC trials. ${ }^{37-40}$ We hypothesised that autophagy induction could mediate resistance to EGFRtargeted therapy, as previously shown in the context of BCR/ ABL pharmacological inhibition. ${ }^{17}$ Unlike in CML, PI3K- and $K R A S$-activating mutations are present in a significant proportion of CRC patients and are associated with resistance to EGFR-targeted therapy and tumour aggressiveness. ${ }^{41,42}$ Constitutive PI3K signalling could inhibit autophagy via mTORC1, whereas KRAS mutations are predicted to either inhibit (via PI3K/mTORC1) or activate autophagy. 5,6 Therefore, we first investigated whether EGFRtargeted therapy could induce autophagy in a panel of CRC cell lines in relation to KRAS and PIK3CA mutational status (Supplementary Figure $1 \mathrm{a}-\mathrm{c}$ ). All cell lines were treated with two different Cetuximab concentrations and LC3B levels were detected by immunoblotting. We also included chloroquine (CQ) treatment to measure autophagic flux. ${ }^{43}$ Only DiFi cells (KRAS and PIK3CA WT) were found to significantly induce autophagy upon Cetuximab at both concentrations examined (Figure 1a). HCT-116 and DLD-1 both KRAS WT and mutant cells (PIK3CA mutant) as well as KRAS mutant $\mathrm{CaCo} 2$ (PIK3CA WT) cells failed to induce autophagy by Cetuximab (Figures 1b-d).

As constitutive PI3K signalling is expected to inhibit mTORC1-regulated autophagy, we next examined the activation status of the PI3K/AKT/mTORC1 pathway upon Cetuximab treatment. We observed that pAKT $\$ 473$ was not downregulated in $\mathrm{CaCo} 2$ cells, whereas it was reduced in HCT-116, DLD-1 and DiFi cells, with the latter exhibiting the most potent downregulation (Figures 1e-h). mTORC1 activation downstream of AKT phosphorylation was assessed by detecting changes in phosphorylation of S6 ribosomal protein at S240/244 (pS6). We observed that pS6 was not altered in HCT-116, CaCo2 and DLD-1 cells (Figures $1 \mathrm{f}-\mathrm{h}$ ), whereas it was abolished in DiFi cells (Figure 1e). Overall, these data suggest a correlation between KRAS and/or PI3K/AKT/ mTORC1 activation and the failure to induce autophagy in CRC cells.

To establish a link between AKT activation levels and mTORC1-mediated autophagy induction upon Cetuximab treatment, we examined whether the use of an AKT inhibitor (AKTvIII) could de-repress autophagy in PIK3CA-mutated cells following Cetuximab treatment. Only the combination of AKTvIII and Cetuximab was able to significantly induce autophagy in DLD-1 KRAS WT cells, whereas either AKTVIII or Cetuximab alone did not alter autophagic flux (Figure 1i). DLD-1 KRAS G13D cells showed a trend, although not significant, in inducing autophagy following AKTvlll alone or in combination with Cetuximab (Figure 1i). AKTvlll alone or in combination with Cetuximab abolished pAKT levels compared with untreated or Cetuximab-only treated conditions in PIK3CA-mutated DLD-1 KRAS WT and mutant cells (Figure 1j). Importantly, only in DLD-1 KRAS WT cells where pS6 levels were abolished (Figure 1k), was autophagy significantly induced upon AKTvIII in combination with Cetuximab.

mTORC1-independent basal autophagy regulates RTK phosphorylation in CRC cells. Our findings indicate that constitutive mTORC1 pathway activation in PIK3CA- and/or KRAS-mutated CRC cells renders them refractory to autophagy induction upon RTK inhibition. However, we noted that despite mTORC1 activation, CRC cells displayed basal levels of autophagy in unstimulated conditions (Figures 2a-d). Specifically, basal autophagy was independent of KRAS and PIK3CA mutational status, as both KRAS WT and mutant as well as PIK3CA WT and mutant CRC cell lines (Supplementary Figure 1a-c) displayed increased LC3-II/ LC3-I ratio following CQ treatment (Figures $2 a-d$ ).

Based on these findings, we investigated the role of mTORC1-independent basal autophagy in CRC cells. We employed an approach for genetically modulating basal

\footnotetext{
Figure 1 The majority of CRC cells are incompetent for autophagy induction following EGFR-targeted therapy owing to constitutive mTORC1 signalling. (a-d) Levels of autophagy induction following EGFR-targeted therapy in CRC cells. CRC cells ((a) DiFi; (b) HCT-116; (c) CaCo2; and (d) DLD-1) were treated with 50 or $100 \mu$ g/ml Cetuximab $\pm 10 \mu \mathrm{M} \mathrm{CQ}$ for $24 \mathrm{~h}$ and total cell lysates were analysed using immunoblot for LC3B protein. Autophagy induction in untreated and Cetuximab-treated CRC cells in the presence and/or absence of CQ was assessed by accumulation of LC3-II levels over LC3-I levels. Bar plots represent densitometric analysis of LC3-II/LC3-I levels. The bars represent mean \pm S.D. of $n=3$; ns $=$ non-statistically significant; ${ }^{\star \star} P<0.01 ;{ }^{* \star *} P<0.001$. Two-way ANOVA statistical analysis was used. (e-k) mTORC1 activation regulates autophagy induction following EGFR-targeted therapy. (e-h) Immunoblots depict PI3K and mTORC1 pathway activation of CRC cells ((e) DiFi; (f) HCT-116; (g) CaCo2 and (h) DLD-1) following EGFR-targeted therapy (50 or $100 \mu \mathrm{g} / \mathrm{ml}$ Cetuximab for $24 \mathrm{~h}$ ). Phosphorylation levels of AKT at S473 residue depict PI3K pathway activation and phosphorylation levels of S6 ribosomal protein at S240/244 residues depict mTORC1 pathway activation $(n=2)$. (i) Levels of autophagy induction following AKT inhibition in combination with EGFRtargeted therapy in PIK3CA mutant DLD-1 cells. DLD-1 KRAS WT and G13D cells were treated with $2 \mu \mathrm{M}$ AKTi vlll $\pm 50 \mu \mathrm{g} / \mathrm{ml}$ Cetuximab $\pm 10 \mu \mathrm{M}$ CQ for $24 \mathrm{~h}$. Autophagy induction was assessed in total cell lysates using immunoblot for LC3B. Bar plots represent levels of autophagy as densitometric analysis of LC3-II/LC3-I levels. The bars represent mean \pm S.D. of $n=3$; ns $=$ non-statistically significant; ${ }^{* \star *} P<0.001$. One-way ANOVA statistical analysis was used. (j-k) Phosphorylation levels of $S 6$ ribosomal protein are inversely correlated with autophagy induction. Immunoblots present phosphorylation levels of AKT and S6 ribosomal protein following $2 \mu \mathrm{M}$ AKTi vlll $\pm 50 \mu \mathrm{g} / \mathrm{ml}$ Cetuximab for $24 \mathrm{~h}$. Levels of $\beta$-actin were used as immunoblot loading controls. *Represents heavy chain or light chain of Cetuximab antibody in Cetuximab-treated cells, which was detected at $\sim 55 \mathrm{kDa}$ below pAKT S473 and total AKT bands and at $\sim 25 \mathrm{kDa}$ below total S6 ribosomal protein bands, respectively
} 
a

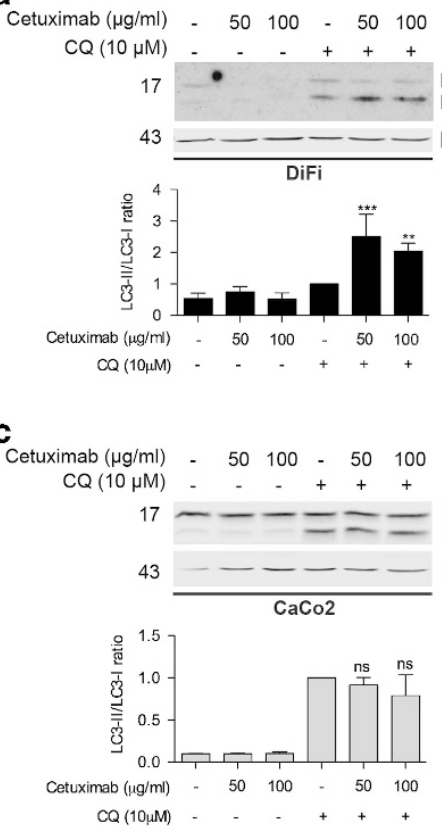

e

$$
\begin{aligned}
& \text { Cetuximab }(\mu \mathrm{g} / \mathrm{ml}) \quad-\quad 50100 \\
& 60-\cdots \text { PAKT S473 } \\
& 60-={ }_{\star}^{\text {Total AKT }} \\
& { }^{43} \underline{\mathrm{DiFi}}^{\beta \text {-actin }}
\end{aligned}
$$

Cetuximab $(\mu \mathrm{g} / \mathrm{ml}) \quad-\quad 50100$ pS6 rib protein

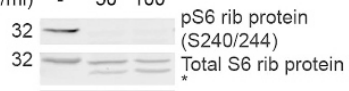$$
43-{ }_{\text {DiFi }}^{\beta-a c t i n}
$$

h

$$
\begin{aligned}
& \text { Cetuximab }(\mu \mathrm{g} / \mathrm{ml}) \quad-\quad 50 \quad 100 \quad-50 \quad 100
\end{aligned}
$$

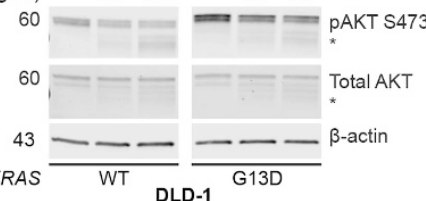

$$
\begin{aligned}
& \text { Cetuximab }(\mu \mathrm{g} / \mathrm{ml}) \text { - } 50 \quad 100 \quad-50100 \quad \mathrm{pS6} \text { rib protein }
\end{aligned}
$$

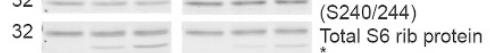

$$
\begin{aligned}
& { }_{\text {KRAS }}^{43}=-\frac{-{ }_{\text {WT }}^{\text {G13D }}}{{ }^{* a c t i n}}
\end{aligned}
$$

j

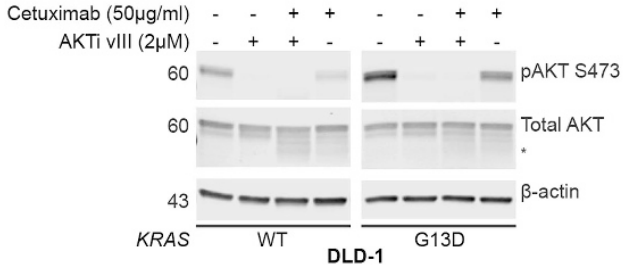

f

b

$\begin{array}{rllllllllllll}\text { Cetuximab }(\mu \mathrm{g} / \mathrm{ml}) & - & 50 & 100 & - & 50 & 100 & - & 50 & 100 & - & 50 & 100 \\ \mathrm{CQ}(10 \mu \mathrm{M}) & - & - & - & + & + & + & - & - & - & + & + & +\end{array}$

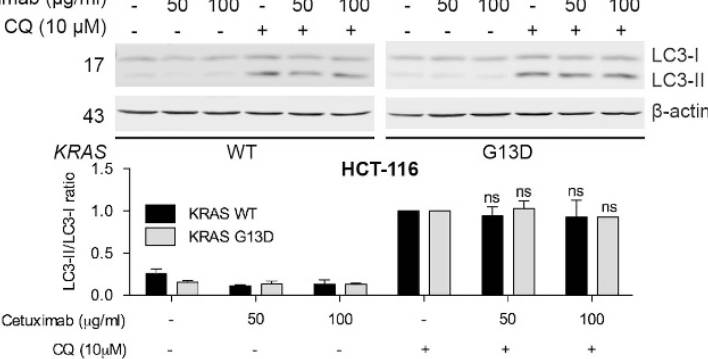

d

Cetuximab $(\mu \mathrm{g} / \mathrm{ml}) \quad$ - $50 \quad \begin{array}{llllllllll}50 & 100 & 50 & 100 & - & 50 & 100 & - & 50 & 100\end{array}$

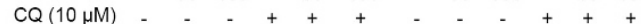

$17-\div-\div-\div-\div$ LC3-1

$43=------^{-a c t i n}$

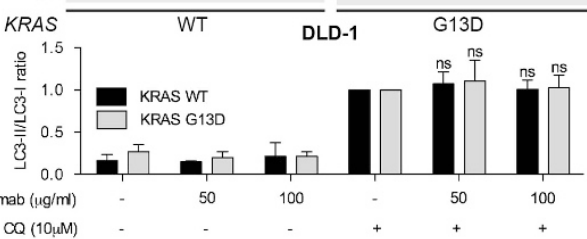

$$
\begin{aligned}
& \text { Cetuximab }(\mu \mathrm{g} / \mathrm{ml}) \quad-\quad 50 \quad 100 \quad-50 \quad 100 \\
& 60--\longrightarrow \text { PAKT S473 } \\
& 60-\div-\longrightarrow \text { Total AKT } \\
& { }_{\text {KRAS }}^{43}=-\frac{-{ }_{\text {WT }}^{\text {HCT-116 }}}{{ }^{\mathrm{G} 13 \mathrm{D}}}
\end{aligned}
$$

Cetuximab $(\mu \mathrm{g} / \mathrm{ml}) \quad-\quad 50100 \quad-50100$ pS6 rib protein

$$
\begin{aligned}
& 32---\ldots-\begin{array}{l}
\text { pS6 rib protein } \\
\text { (S240/244) }
\end{array} \\
& 32-\div-\div \text { Total S6 rib protein }
\end{aligned}
$$

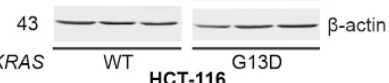$$
\text { g }
$$$$
\text { Cetuximab }(\mu \mathrm{g} / \mathrm{ml}) \quad-50100
$$

$$
\begin{aligned}
& 60-\text { PAKT S473 } \\
& 60-\text { Total AKT }^{-}{ }^{\text {CaCo2 } 2}
\end{aligned}
$$

Cetuximab $(\mu \mathrm{g} / \mathrm{ml}) \quad-\quad 50100 \quad$ pS6 rib protein $32 \_$pS6 rib prote

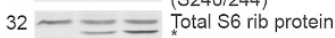$$
43-\beta \text {-actin }
$$

\section{i}

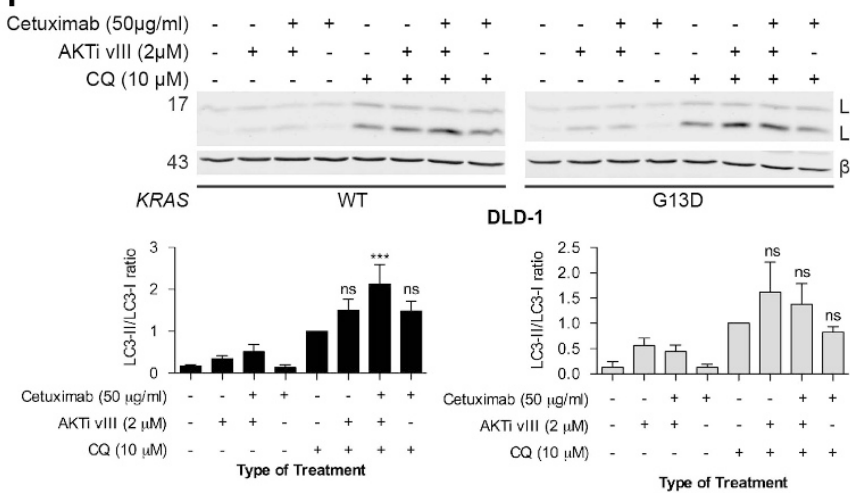

K

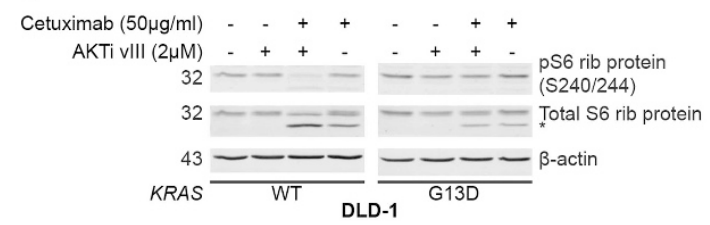


autophagy using a doxycycline (Dox)-inducible shRNA against ATG7, an essential autophagy gene (Figures 2e-g). ATG7 downregulation significantly reduced levels of basal autophagy in HCT-116, DLD-1 (both KRAS WT and mutant) and $\mathrm{CaCo} 2$ autophagy-compromised cells (Figures $2 \mathrm{e}-\mathrm{g}$ ). In addition, we used CRISPR/Cas9 technology for knocking out ATG7 or ATG5 genes (ATG7 and ATG5 KO), which abolished basal autophagy in HCT-116 cells (Figure $2 \mathrm{~h}$ ). We hypothesised that autophagy might not have a significant degradative role in CRC cells under non-starved conditions. We examined the levels of p62, an autophagy adaptor targeting polyubiquitinated proteins and organelles for lysosomal degradation through binding LC3 on phagophore membranes. Inhibition of autophagy results in accumulation of p62 levels. ${ }^{44}$ However, in CRC cells, p62 levels were not significantly affected by either $\mathrm{CQ}$ or inhibition of autophagy via a Dox-inducible shRNA against ATG7 (Figures 2e-g). Downregulation of autophagy in ATG7 KO HCT-116 cells significantly upregulated p62 levels, but this was not evident in ATG5KO HCT-116 cells (Figure $2 \mathrm{~h}$ ). As autophagy inhibition did not consistently affect p62 levels, we decided to investigate its effect on other cellular functions, in particular cell signalling, which was reported to be regulated by autophagy. ${ }^{4,46}$ Given the key role of RTKs in CRC pathogenesis, we explored the role of autophagy in RTK activation. To this end, we utilised a phospho-RTK array covering 49 different RTKs. Activated KRAS G13D isogenic cell lines were also examined to assess whether presence of oncogenic KRAS affects autophagy-dependent RTK regulation. Interestingly, phosphorylation of eight different RTKs was decreased upon autophagy suppression in HCT-116 KRAS WT cells (Figures $3 a$ and b). In particular, autophagycompromised cells displayed a decrease in phosphorylation levels of the highly activated RTKs: (i) c-MET (35\%), (ii) Dtk (35\%), (iii) c-Ret (60\%) and (iv) RYK (40\%). In the same cells, RTKs with lower phosphorylation levels were also affected, such as TrkC (90\%), EphA1 (46\%), EphA2 (30\%) and EphB2 (60\%). RTK phosphorylation was also affected in autophagy-suppressed KRAS G13D HCT-116 cells: c-Ret (60\%), c-Met (47\%), MSP receptor (42\%), EphA10 (38\%), Dtk (30\%), Insulin Receptor (26\%), IGF-I receptor (22\%), AxI (17\%) and ROR2 (15\%) (Figures 3a and c). To exclude a cell type-specific effect, DLD-1 KRASWT and G13D cells were also examined for RTK activation levels upon autophagy suppression. Consistent with the reduced RTKphosphorylation phenotype observed in HCT-116 autophagycompromised cells, both DLD-1 KRAS WT and G13D autophagy-compromised cells displayed decreased phosphorylation of several RTKs (Supplementary Figure $2 a-c$ ).
Therefore, autophagy suppression reduced phosphorylation of several RTKs in CRC cells, in most cases independently of KRAS mutational status.

Basal autophagy regulates c-MET phosphorylation. We focused on C-MET, which has an oncogenic role in CRC and has been implicated in the development of primary and acquired resistance of metastatic CRC cells and patients to EGFR-targeted therapy. ${ }^{42,47}$ In keeping with the phospho-RTK array results, immunoprecipitated total c-MET was found less phosphorylated in autophagy-compromised cells compared with autophagy-proficient HCT-116 KRAS WT cells (Figure 4a). In contrast, phosphorylation levels of both IGF-IR and EGFR were unaltered following basal autophagy suppression, confirming phospho-RTK array results (Supplementary Figure $3 a-b)$. Notably, total tyrosine-phosphorylation levels were unaffected upon autophagy suppression (Figure 4a). We further confirmed that basal autophagy suppression reduces phosphorylation of c-MET using a phospho-specific c-MET antibody. The ratio of $\mathrm{p}-\mathrm{c}-\mathrm{MET}$ to total $\mathrm{c}-\mathrm{MET}$ was decreased in lysates from autophagy-compromised HCT-116 KRASWT and G13D cells ( $40 \%$ and $30 \%$, respectively; (Figure $4 \mathrm{~b})$ ). p-c-MET was consistently reduced in ATG7 and ATG5 KO HCT-116 cells (Figure 4c) or in autophagy-compromised CaCo2 cells (Figure 4d). Total c-MET levels were unaffected upon autophagy inhibition (Figures $4 \mathrm{~b}-\mathrm{d}$ ). Although autocrine c-MET activation in CRC has been described, ${ }^{48}$ we did not detect any differences in endogenous HGF expression in lysates from ATG7 knockdown cells neither in the presence nor absence of $C Q$ (Supplementary Figure 3c). In addition, no significant difference in secreted HGF was evident between autophagy-proficient and deficient ATG7 or ATG5 KO HCT-116 cells using enzyme-linked immunosorbent assay (ELISA) assays (Supplementary Figure $3 d$ ), indicating that differences in $\mathrm{p}$-c-MET are not owing to increased autocrine/paracrine HGF signalling.

We next investigated the functional implications of the diminished phosphorylation of c-MET observed in autophagyimpaired conditions. Given the well-described role of c-MET in regulation of cell migration and proliferation, ${ }^{49}$ we hypothesised that autophagy suppression could reduce migration and proliferation capacity of CRC cells in nutrient/growth factor-replete conditions. To study the role of basal autophagy in CRC migration, we used a transwell assay whereby cell migration was examined using HGF as a chemoattractant. We found that ATG7 and ATG5 KO HCT-116 cells present a significant decrease in migration capacity compared with autophagy-proficient cells ( $30 \%$; Figure $4 \mathrm{e})$. To assess the

Figure 2 Monitoring and genetic modulation of basal autophagic flux in CRC cell lines. (a-d) Immunoblots show representative images of basal autophagic flux levels in CRC cells. CRC cells ((a) HCT-116; (b) DLD-1; (c) CaCo2 and (d) DiFi) were treated $\pm 10 \mu \mathrm{M} \mathrm{CQ}$ for $6 \mathrm{~h}$ and total cell lysates were analysed using immunoblot for LC3B protein. Accumulation of LC3-II over LC3-I band following CQ treatment depicts basal autophagic flux of CRC cells. Levels of $\beta$-actin were used as immunoblot loading controls. (e-g) Examination of autophagic flux and p62 protein levels in autophagy-proficient and compromised CRC cells, developed via using a Dox-inducible shRNA system against ATG7. Autophagy-proficient (shEGFP) and autophagy-compromised (shATG7) CRC cells ((e) HCT-116, $n=3$; (f) DLD-1, $n=3$; and (g) CaCo2, $n=3$ ) were treated with Dox for 5 days to efficiently downregulate ATG7 protein and total cell lysates were subjected to immunoblot analysis for ATG7, p62 and LC3B protein levels. $\beta$-actin was used as loading control. (h) Examination of autophagic flux and p62 protein levels in autophagy-proficient and deficient HCT-116 cells, developed via using the CRISPR/Cas9 technology for knocking out ATG7 or ATG5 genes, $n=4$. Total cell lysates were subjected to immunoblot analysis for ATG7, ATG5, p62 and LC3B protein levels. $\beta$-actin was used as loading control. Bar plots represent densitometric analysis of LC3-II/LC3-I levels and p62 levels normalised to $\beta$-actin. The bars represent mean \pm S.D.; ns $=$ non-statistically significant; ${ }^{*} P<0.05$; ${ }^{* *} P<0.01 ;{ }^{* *} P<0.001$. One-way and two-way ANOVA statistical analysis was used for p62 and autophagic flux analysis, respectively 
a

$$
\begin{aligned}
& \begin{array}{c}
\mathrm{CQ}(\mathrm{\mu M}) \\
17-10-10 \\
\text { LC3-1 }
\end{array}
\end{aligned}
$$

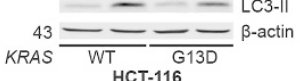

b

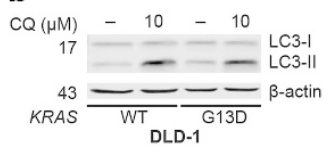

C

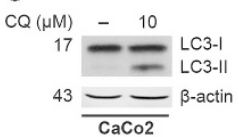

d

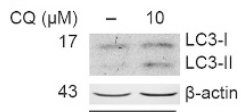

e

ShEGFP + . + +

ShATG7 E8 - + - +
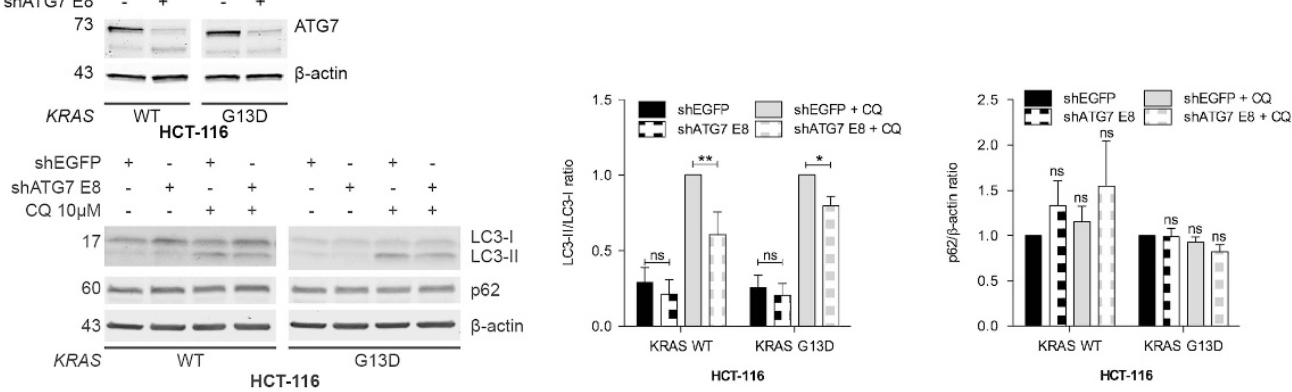

f

ShEGFP
ShATG7 E8

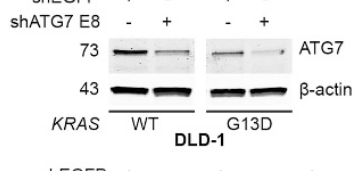

ShEGFP + - + - + - +

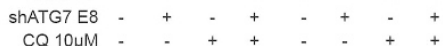

$17-\frac{-1}{-1}-\square=$ LC3-1

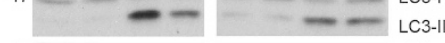

60 - - - -

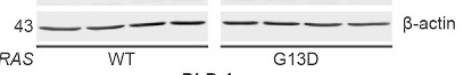
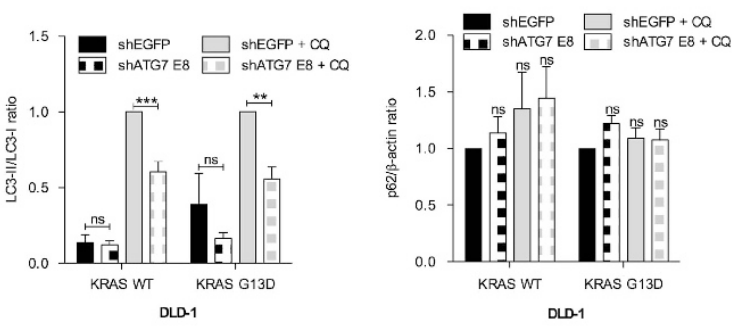

$\mathbf{g}$

ShEGFP +-
ShATG7

ShATG7 - E8
$73=$ ATG7

$43 \square \beta$-actin

$\overline{\mathrm{CaC} O 2}$

ShEGFP + - +
ShATG7 - E8 - E8

ShATG7 - E8 - E8
CQ10MM - - +

17 - $\mid$ 二二

$60-1-{ }^{\mathrm{p} 62}$

${ }^{43--_{-1}}{ }^{\beta-a c t i n}$
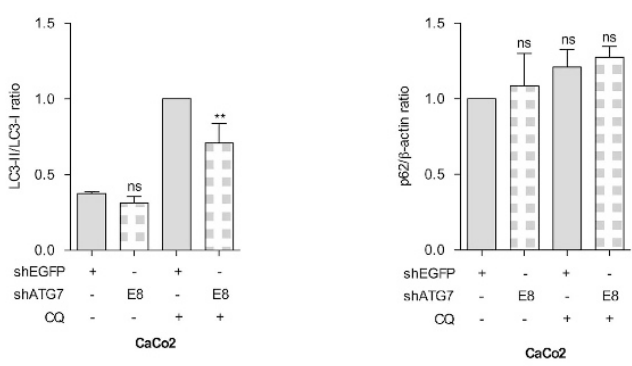

h

Ctrl gRNA + - .

ATG7 gRNA
ATG5 gRNA

$73- \pm$ - $\mathrm{ATG7}$

$55-$ ATG5
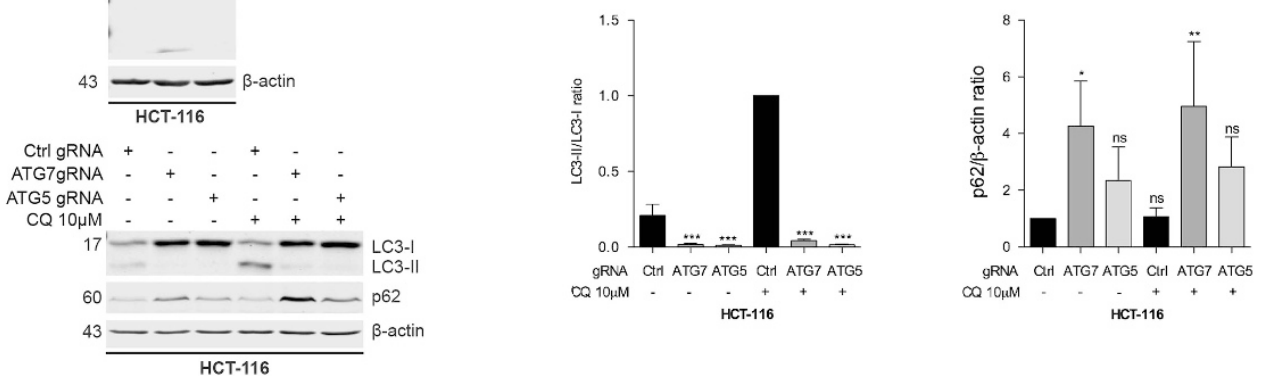
a
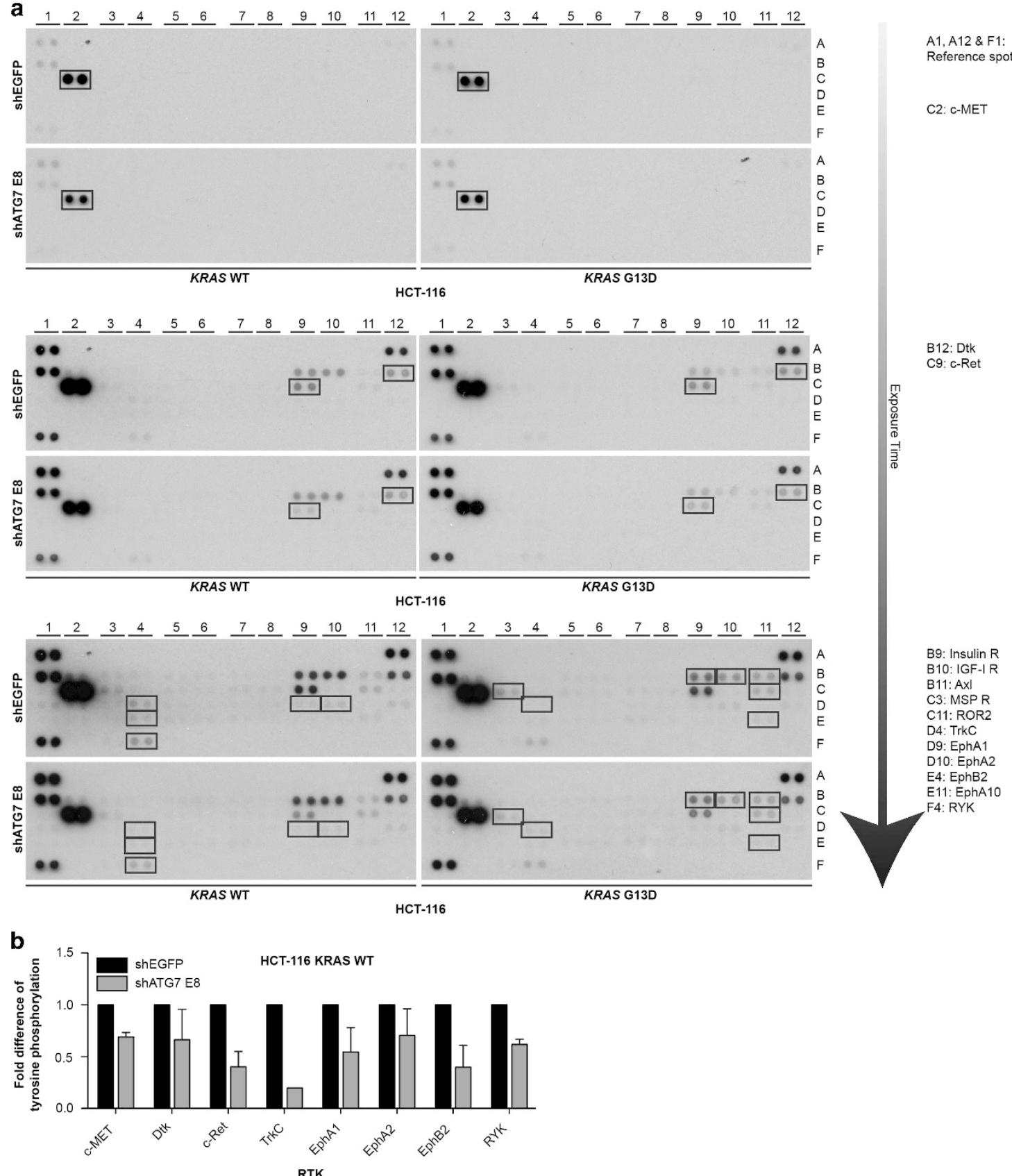

RTK

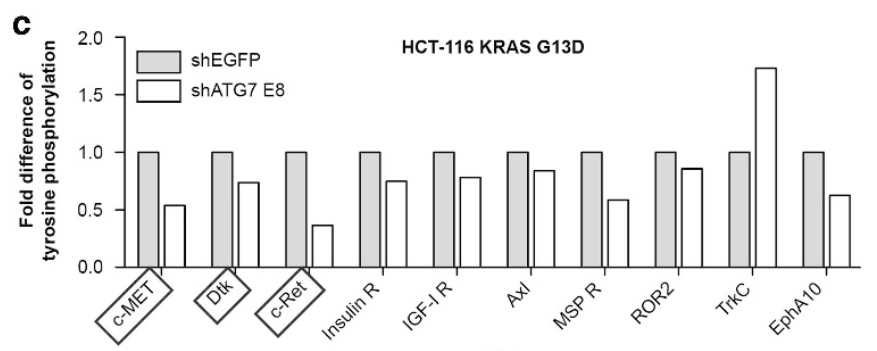

RTK

Figure 3 Genetic modulation of autophagy reduces phosphorylation of RTKs in HCT-116 KRAS WT and G13D isogenic cells. Autophagy-proficient (shEGFP) and autophagycompromised (shATG7 E8) cells were treated with $10 \mathrm{ng} / \mathrm{ml}$ Dox for 5 days to efficiently downregulate ATG7 protein and total cell lysates were subjected to phospho-RTK array analysis. (a) Immunoblots presented are from one complete experiment, processed simultaneously for all conditions examined and are representative of two independent experiments for KRAS WT and one experiment for KRAS G13D cells. Arrow indicates increased exposure time used to develop immunoblots. $(\mathbf{b}, \mathbf{c})$ Bar plots depict densitometric quantification of phosphoRTK array spots. Bars represent mean \pm S.D. Black boxes indicate RTKs found to be deregulated upon autophagy suppression in both HCT-116 KRAS WT (b) and G13D (c) cells 
a

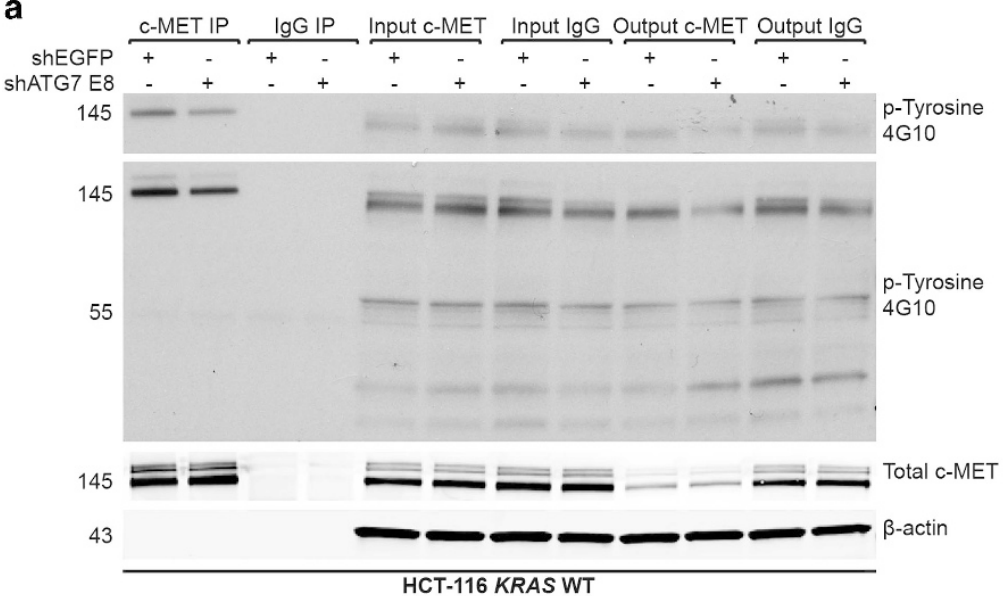

C
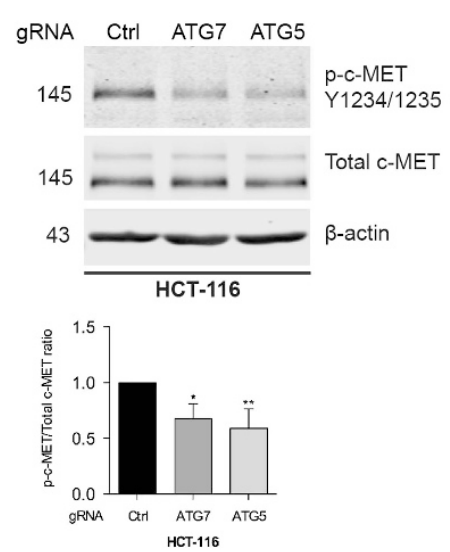

\section{d}
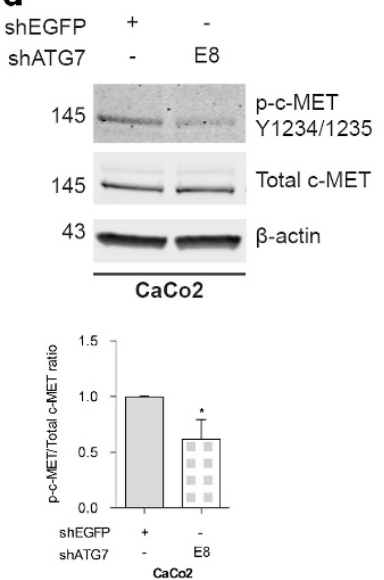

b

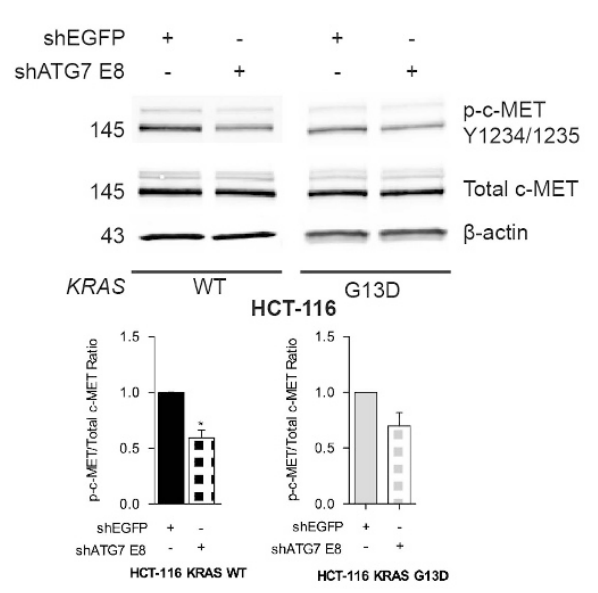

e
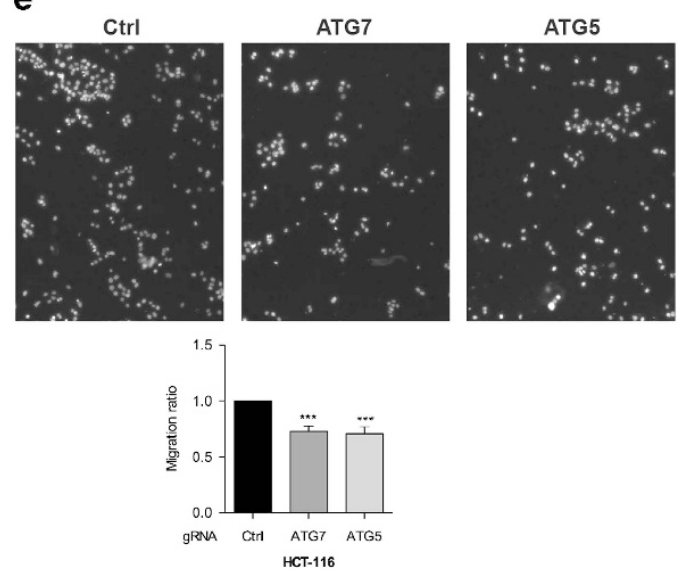

Figure 4 Autophagy suppression reduces phosphorylation of c-MET and diminishes migration capacity of CRC cells towards HGF. (a) Total c-MET immunoprecipitation showing reduced c-MET phosphorylation in autophagy-compromised HCT-116 KRASWT cells. Autophagy-proficient (shEGFP) and compromised (shATG7 E8) cells 5 days after $10 \mathrm{ng} / \mathrm{ml}$ Dox treatment were lysed and total c-MET protein subjected to immunoprecipitation. Immunoprecipitated c-MET phosphorylation was assessed using immunoblotting for p-Tyrosine 4G10 antibody. Total c-MET was used to examine immunoprecipitation efficiency and loading. $\beta$-actin was used as loading control of total cell lysates $(n=1)$. (b) Immunoblot showing reduced phosphorylation of c-MET Y1234/1235 catalytic subunit residues in autophagy-compromised HCT-116 KRAS WT and G13D cells. Autophagyproficient (shEGFP) and compromised (shATG7 E8) cells were treated with $10 \mathrm{ng} / \mathrm{ml} \mathrm{Dox}$ for 5 days and total cell lysates were subjected to immunoblotting for p-c-MET Y1234/1235 and total c-MET protein levels. $\beta$-actin was used as loading control. Bar plots represent densitometric quantification of $p$-c-MET Y1234/1235 relative to total c-MET protein. The bars represent mean \pm S.D. of $n=3$ (HCT-116 KRASWT) and $n=2$ (HCT-116 KRAS G13D); ${ }^{*} P<0.05$. Unpaired Student's $t$-test statistical analysis was used for HCT-116 KRASWT cells $(n=3)$. (c) Immunoblot showing reduced phosphorylation of c-MET Y1234/1235 catalytic subunit residues in autophagy-deficient HCT-116 cells. Total cell lysates of autophagy-proficient (gRNA Ctrl) and deficient (gRNA ATG7 or ATG5) cells were subjected to immunoblotting for p-c-MET Y1234/1235 and total c-MET protein levels. $\beta$-actin was used as loading control. Bar plot represents densitometric quantification of $\mathrm{p}-\mathrm{c}-\mathrm{MET} \mathrm{Y} 1234 / 1235$ relative to total c-MET protein. The bars represent mean $\pm \mathrm{S}$. D. of $n=4$; ${ }^{*} P<0.05 ;{ }^{*} P<0.01$. One-way ANOVA statistical analysis was used. (d) Immunoblot showing reduced phosphorylation of $c-M E T$ Y1234/1235 catalytic subunit residues in autophagy-compromised CaCo2 cells. Autophagy-proficient (shEGFP) and compromised (shATG7 E8) cells were treated with $100 \mathrm{ng} / \mathrm{ml}$ Dox for 5 days and total cell lysates were subjected to immunoblotting for p-c-MET Y1234/1235 and total c-MET protein levels. $\beta$-actin was used as loading control. Bar plots represent densitometric quantification of $p-c-M E T$ Y1234/1235 relative to total c-MET protein. The bars represent mean \pm S.D. of $n=3 ;{ }^{*} P<0.05$. Unpaired Student's $t$-test statistical analysis was used. (e) Autophagy suppression diminishes migration capacity of HCT-116 cells towards HGF. Autophagy-proficient and deficient HCT-116 cells were plated in migration inserts in nutrient-fed conditions and migration capacity of cells was examined after $60 \mathrm{~h}$ using $50 \mathrm{ng} / \mathrm{ml} \mathrm{HGF}$ as a chemoattractant. Migrated cells were fixed and stained by using Hoechst staining. Images of migrated cells were acquired by using a fluorescence microscope and migrated cells were counted by using Cell Profiler software. Bar plot represents ratio of migration between autophagy-proficient and deficient cells. The bars represent mean \pm S.D. of $n=3$; ${ }^{* \star \star} P<0.001$. One-way ANOVA statistical analysis was used

role of basal autophagy in cell proliferation, two different approaches were used. First, the proliferation rate of autophagy-proficient and compromised HCT-116 and DLD-1 cells (both KRAS WT and mutant) was examined under adherent conditions using the Sulforhodamine B (SRB) assay. Basal autophagy suppression did not alter the proliferation rate of both KRAS WT and mutant HCT-116 and DLD-1 cells (Supplementary Figure $3 \mathrm{e}-\mathrm{f}$ ). In addition, we used soft agar assays in autophagy-proficient and deficient HCT-116 cells. ATG7 and ATG5 KO HCT-116 cells showed a trend towards reduction in anchorage-independent cell growth in comparison with autophagy-proficient cells (Supplementary Figure $3 \mathrm{~g}$ ). Overall, autophagy suppression reduces phosphorylation of c-MET and diminishes migration capacity of CRC cells towards HGF, without significant effects on cell proliferation/viability. 
LAMP1-negative, LC3B-positive vesicles colocalise with internalised c-MET. RTKs are suggested to colocalise with autophagic structures ${ }^{50,51}$ and thus autophagy may regulate C-MET by controlling its internalisation and/or intracellular function. To explore this, HCT-116 cells were examined for endogenous C-MET and LC3B protein localisation using confocal microscopy. As HCT-116 cells displayed almost undetectable LC3B-positive vesicles at steady state, we added $\mathrm{CQ}$, which enables autophagosome-detection by interfering with the acidification of lysosomes and inhibiting their proteolytic activity. ${ }^{43}$ Following $\mathrm{CQ}$ treatment, c-MET was observed in intracellular, perinuclear, punctate structures that colocalised with LC3B in autophagy-proficient conditions (Figures $5 \mathrm{a}$ and $\mathrm{b}$ ). To determine whether this colocalisation pattern applied to another RTK, localisation of EGFR was examined upon CQ treatment in HCT-116 KRAS WT cells. In contrast to $\mathrm{C}-\mathrm{MET}$, EGFR neither accumulate in perinuclear areas nor colocalised with LC3B (Supplementary Figure $3 \mathrm{~h}$ ). Although LC3B staining following CQ treatment was abolished in ATG7 and ATG5 KO HCT-116 cells (Figure 5b), the intracellular accumulation of endogenous c-MET was not affected (Figure 5b), suggesting that basal autophagy suppression does not regulate c-MET internalisation.

Ligand-activated c-MET internalisation and trafficking to the lysosomal compartment is one of the main mechanisms for C-MET signalling desensitisation leading to c-MET proteolytic degradation. ${ }^{49}$ To assess whether $\mathrm{CQ}$ treatment results in intracellular c-MET accumulation via inhibiting c-MET lysosomal degradation we followed two different approaches. First, we established a biochemical approach to examine the phosphorylated and total c-MET levels of autophagyproficient and deficient HCT-116 cells in the presence and absence of $C Q$. We found that $C Q$ does not alter total c-MET levels in both autophagy-proficient and deficient HCT-116 cells, whereas it significantly increases p-c-MET only in autophagy-proficient cells ( $38 \%$; Figure $5 \mathrm{c}$ ), suggesting that the increase in c-MET phosphorylation upon CQ is dependent on the presence of autophagosomes. Second, we employed an immunofluorescence (IF) approach whereby we examined the colocalisation pattern of LC3B, C-MET and LAMP1, a lysosomal marker, in HCT-116 cells overexpressing LAMP1 protein linked to RFP in the presence of $C Q$ using confocal microscopy. c-MET was found in two intracellular pools: the first pool $(6.8 \%$ of total intracellular c-MET) colocalised with the lysosomal marker LAMP1 (Figure 5d), whereas the second pool (13.3\% of LAMP1-negative intracellular c-MET) colocalised with LC3B (Figure 5d). Collectively, these data suggest that c-MET association with LC3B-positive, LAMP1negative vesicles may be important for its phosphorylation.

Basal autophagy-mediated regulation of c-MET phosphorylation involves mTORC2 signalling. We further investigated whether reduced RTK phosphorylation observed in autophagy-impaired cells was associated with alterations of cell signalling. We noted that upon Dox treatment, CRC cells displayed reduced mTORC2-mediated phosphorylation of AKT (pAKT S473), relative to total AKT levels (Figures $6 a-c)$. Notably, pAKT S473 downregulation was confirmed in ATG7 or ATG5 KO HCT-116 cells (Figure 6g). Reduced pAKT S473 was not associated with decreased phosphorylation levels of the mTORC1 downstream target, S6 ribosomal protein (Figures $6 d-f$ ). Sustained activation of mTORC1 following autophagy suppression was further confirmed in ATG7 or ATG5 KO HCT-116 cells (Figure 6h). Together, these data suggest that autophagy inhibition affects mTORC2 but not mTORC1 activity.

As inhibition of mTORC2-dependent AKT phosphorylation also occurred in cells with constitutive PI3K signalling, we speculated that these signalling changes are upstream rather than downstream of the defect in RTK phosphorylation. In addition to RTK signalling affecting mTORC2, ${ }^{52}$ mTORC2 alone can positively modulate RTK activation. ${ }^{53}$ Consequently, we investigated whether inhibition of mTORC2 could affect c-MET phosphorylation. We employed small interfering RNA (siRNA)-mediated downregulation of mTORC2 activity via targeting of Rictor (Figure 7a), an essential component of mTORC2 (ref. 54). As expected, Rictor downregulation resulted in decreased pAKT S473, whereas mTORC1dependent signalling was unaltered (Figure 7b). Of note, inhibition of mTORC2 activity led to reduced phosphorylation of c-MET without affecting its total levels (Figure 7b). Importantly, basal autophagy was unaffected by Rictor knockdown (Figure 7c), suggesting that mTORC2 does not control c-MET phosphorylation via regulation of autophagy. To confirm Rictor-siRNA findings, we generated ATG7 WT and ATG7 KO HCT-116 cells where Rictor was knocked out using CRISPR/Cas9. Both autophagy-proficient and deficient HCT-116 cells transfected with Rictor gRNA, displayed reduced levels of Rictor to a similar extent (Figure $7 d$ ). In addition, no significant difference in Rictor expression levels was observed between autophagy-proficient and deficient HCT-116 cells transfected with a control Cas9 vector

\footnotetext{
Figure 5 LC3B-positive vesicles colocalise with internalised c-MET. Representative images from confocal sections of autophagy-proficient (shEGFP) HCT-116 KRAS WT cells (a) as well as autophagy-proficient (gRNA Ctrl) and deficient (gRNA ATG7 or ATG5) HCT-116 cells (b) showing total c-MET colocalising with LC3B-positive intracellular structures. For (a) cells were treated with $10 \mathrm{ng} / \mathrm{ml}$ Dox for 5 days. For (a-b) cells were treated with $10 \mu \mathrm{M} \mathrm{CQ}$ for $6 \mathrm{~h}$, fixed and stained for total c-MET (green), LC3B (red) and nucleus (Hoechst dye-blue). Scale bar corresponds to $5 \mu \mathrm{m}$. Orthogonal reconstruction of serial confocal slices is shown ( $Y-Z$ and $X-Z$ axis with 1: merge of total c-MET/LC3B/ Hoechst; 2: total c-MET; 3: LC3B). Yellow lines on the confocal section indicate from where the orthogonal views were built. (c) CQ treatment increases phosphorylation of c-MET only in autophagy-proficient, whereas does not alter total c-MET levels. Autophagy-proficient (gRNA Ctrl) and deficient (gRNA ATG7 or ATG5) cells were treated $\pm 10 \mu \mathrm{M}$ CQ for $6 \mathrm{~h}$ and total cell lysates subjected to immunoblotting for $\mathrm{p}$-c-MET Y1234/1235 and total c-MET protein levels. $\beta$-actin was used as loading control. Bar plot represents densitometric quantification of p-c-MET Y1234/1235 relative to total c-MET protein or total c-MET levels normalised to $\beta$-actin. The bars represent mean \pm S.D. of $n=4$; ns $=$ non-statistically significant; ${ }^{*} P<0.05 ;{ }^{* *} P<0.01 ;{ }^{* *} P<0.001$. One-way ANOVA statistical analysis was used. (d) $3 D$ reconstruction and $3 D$ reconstruction of spots from serial confocal slices were built using Imaris to examine the triple colocalisation of LC3B, C-MET and LAMP1 proteins in HCT-116 cells overexpressing LAMP1 protein linked to RFP in the presence of $10 \mu \mathrm{M}$ of CQ for $6 \mathrm{~h}$. Cells were stained for total c-MET (green), LC3B (magenta), RFP (red) and nucleus (Hoechst dye-blue). Scale bar corresponds to $5 \mu \mathrm{m} ; n=45$ cells
} 
a

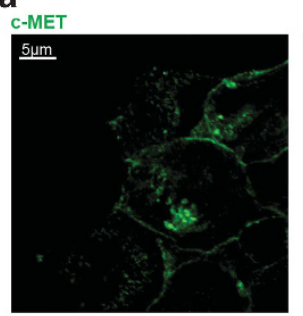

C-MET / LC3B / Hoechst
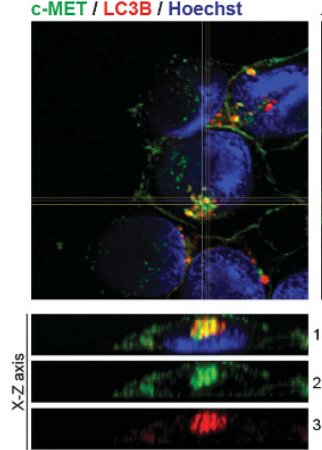

b
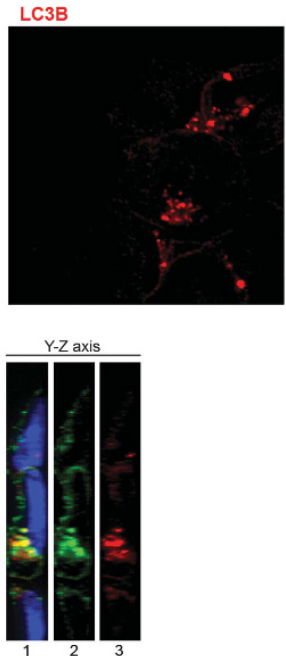

C

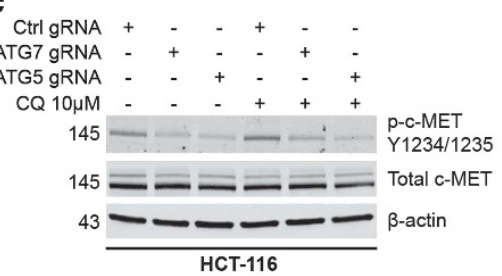

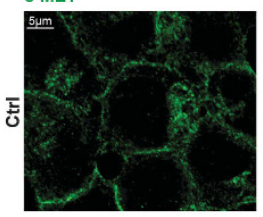

LC3B

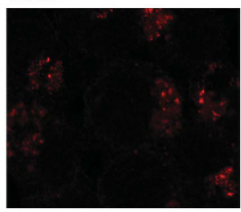

LC3B
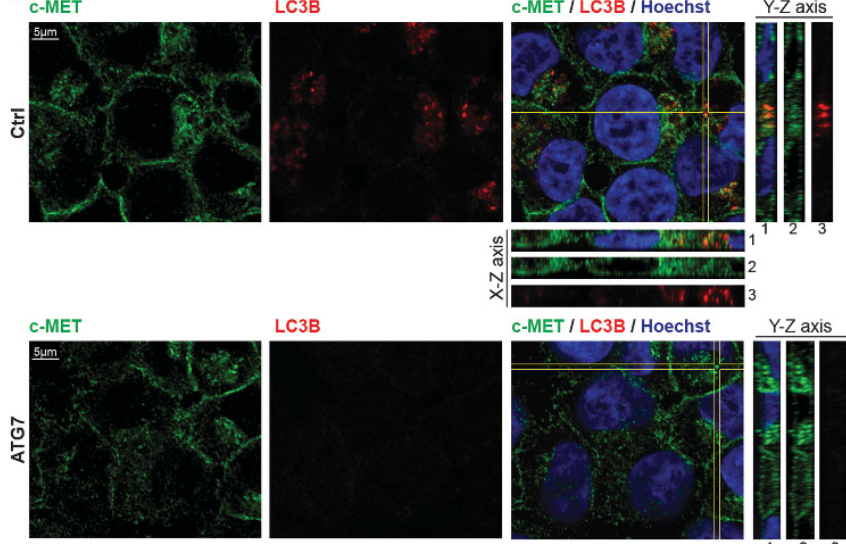

C-MET / LC3B / Hoechst
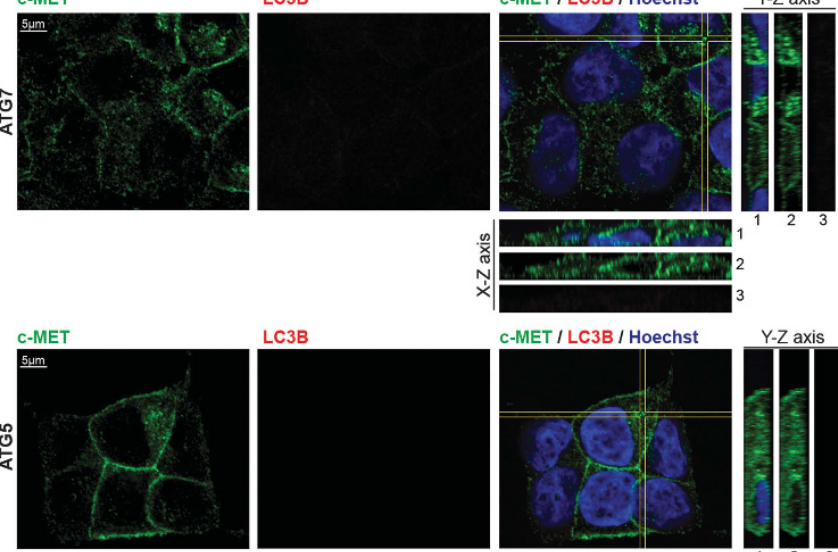

C-MET / LC3B / Hoechst
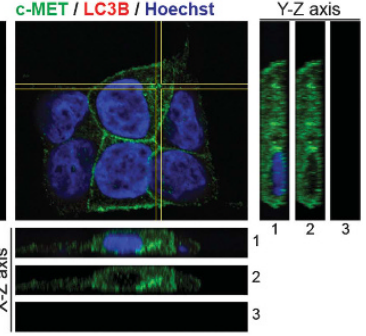

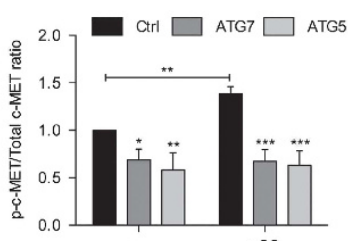

$+\infty$

C Crr $\square$ ATG7 $\square$ ATG5

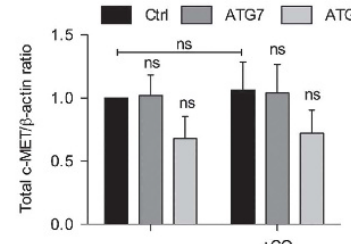

Type of treatment

d $_{\text {C-MET / LC3B / LAMP1/ Hoechst }}$
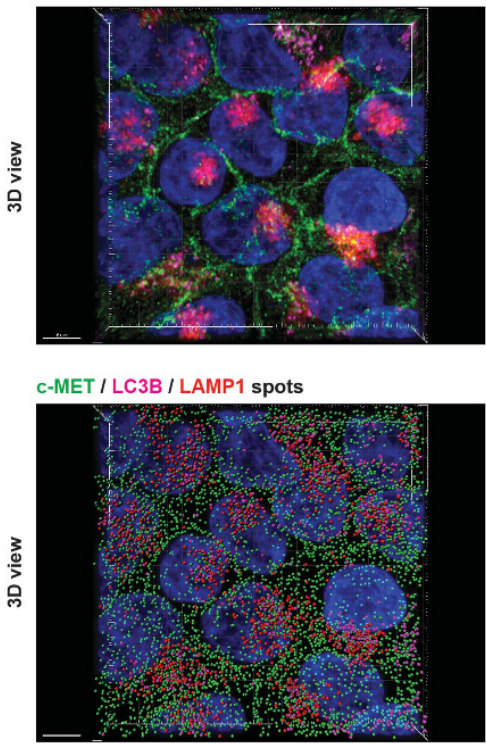

c-MET / LAMP1 / Hoechst

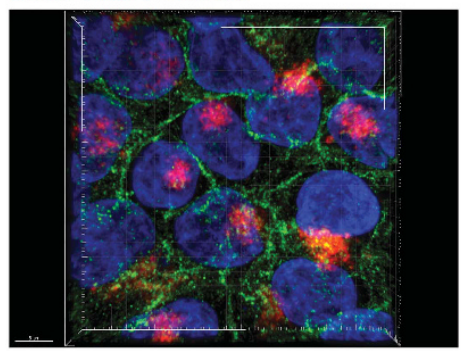

c-MET colocalising LAMP1; $6.8 \%$

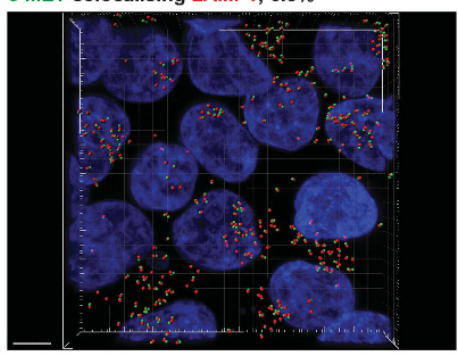

C-MET / LC3B / Hoechst

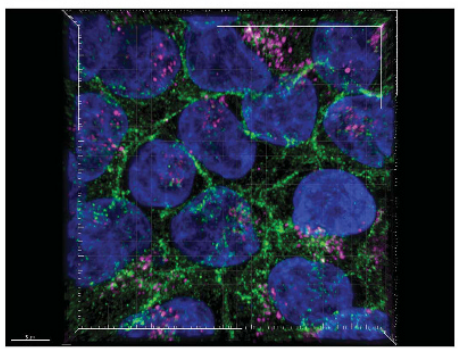

c-MET not colocalising LAMP1colocalising LC3B; $13.3 \%$

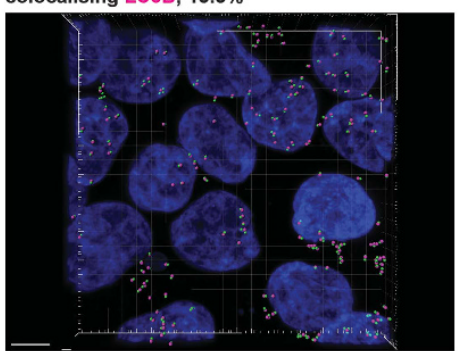


(Figure 7d). Consistently with Rictor-siRNA results, Rictor KO led to downregulation of $\mathrm{p}-\mathrm{c}-\mathrm{MET}$ and did not alter mTORC1 signalling (Figure 7e). Intriguingly, Rictor KO decreased c-MET phosphorylation in autophagy-proficient cells to the similar extent as autophagy suppression and did not further reduce $\mathrm{p}$-c-MET in autophagy-deficient cells (Figure 7e).

We further investigated whether mTORC2-activity inhibition affects $\mathrm{C}-\mathrm{MET}$ localisation or $\mathrm{C}-\mathrm{MET}$ interaction with a

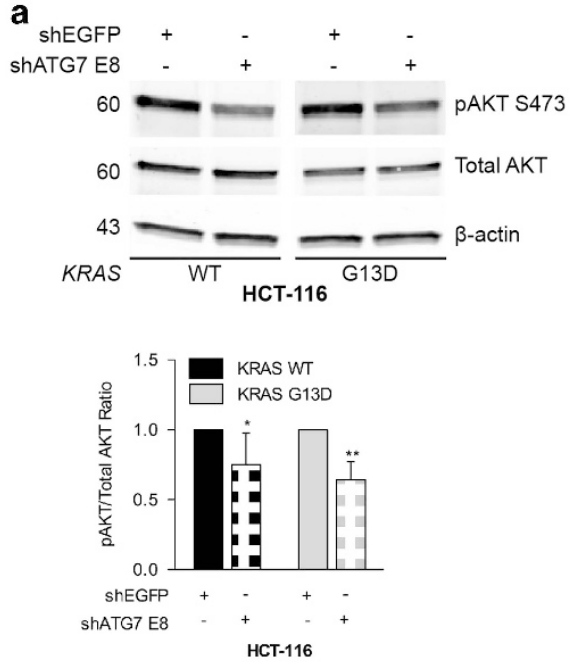

d
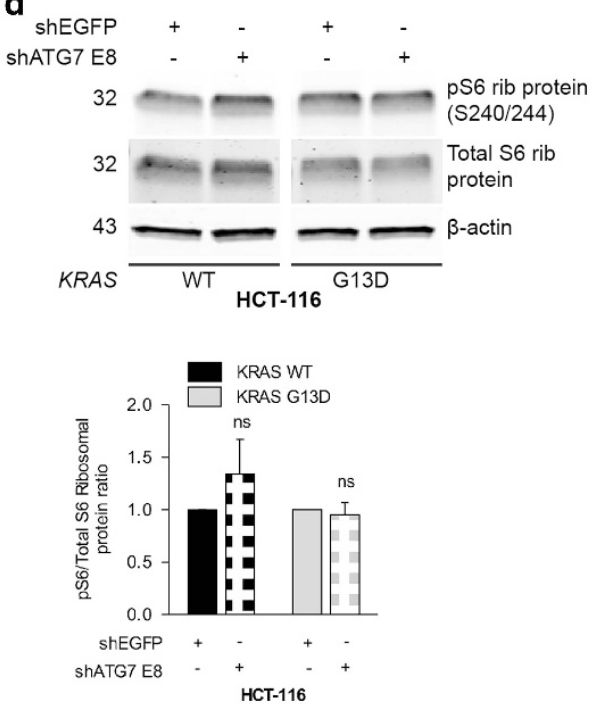

g

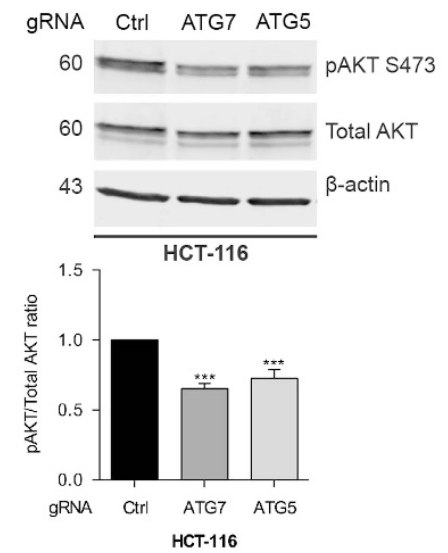

b
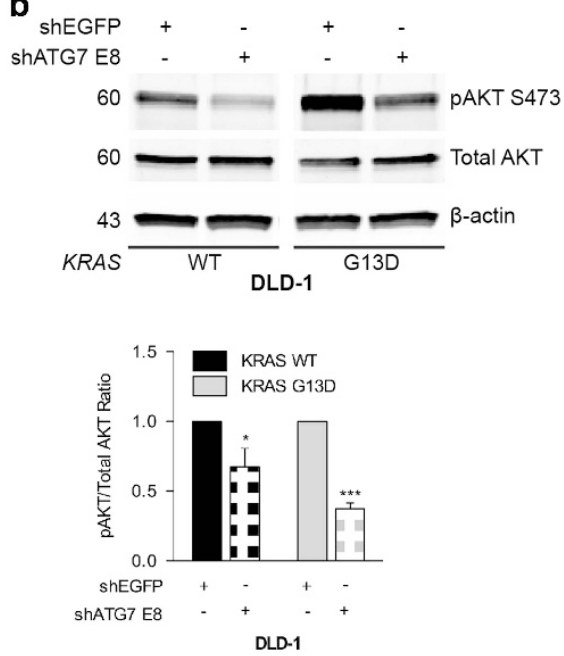

e
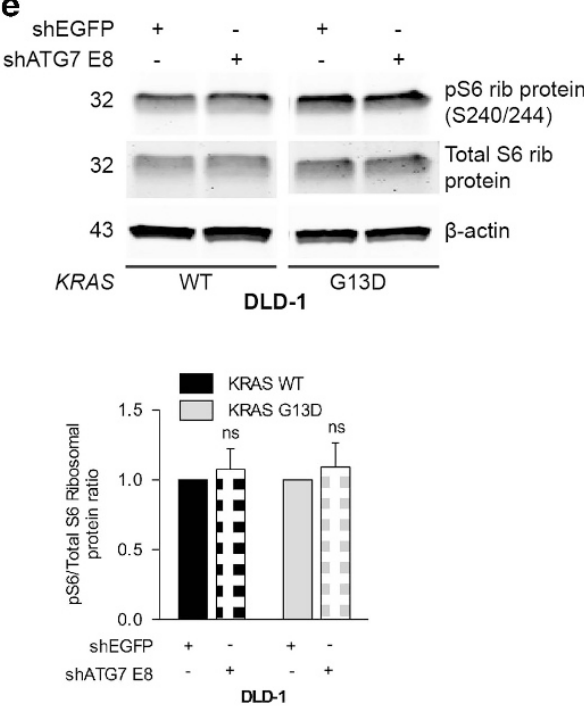

h

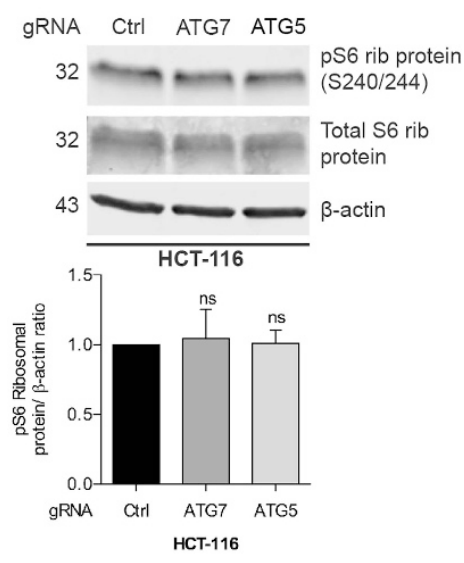

C ShEGFP + shATG7 E8
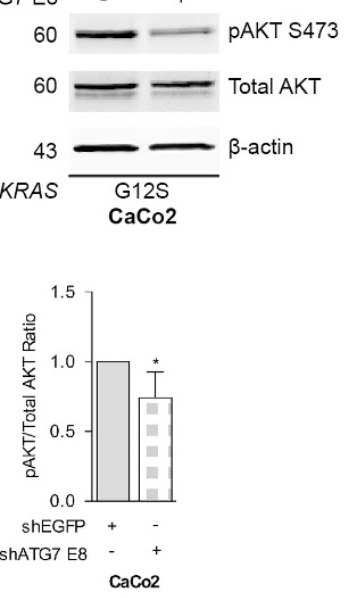

f
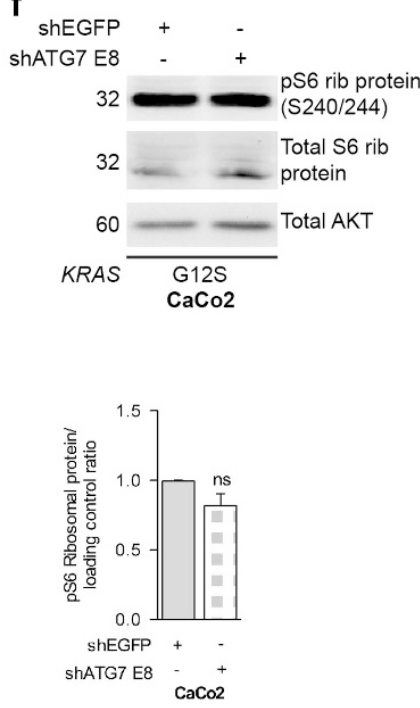
LC3B-positive intracellular structures using confocal microscopy in autophagy-proficient Rictor WT or KO HCT-116 cells in the presence of $\mathrm{CQ}$. Rictor $\mathrm{KO}$ and consequently inhibition of mTORC2 activity did not affect $\mathrm{c}-\mathrm{MET}$ internalisation or its accumulation in intracellular LC3B-positive structures (Figure 7f), suggesting that lack of Rictor does not affect the interaction of LC3B vesicles with c-MET but rather impinges on the functional consequences of such interaction.

To assess whether pharmacological inhibition of mTOR phenocopies Rictor downregulation, we employed the mTOR kinase inhibitor Torin2, which suppresses both mTORC1 and mTORC2. Torin2 downregulated pAKT S473 as well as pS6 ribosomal protein downstream of $\mathrm{mTORC} 1$ in both autophagyproficient and autophagy-compromised cells (Figure $7 \mathrm{~g}$ ). Interestingly, Torin2 decreased c-MET phosphorylation to a similar extent as the suppression of autophagy. Moreover, Torin2 did not further reduce $\mathrm{p}-\mathrm{c}-\mathrm{MET}$ in autophagycompromised conditions (Figure 7g). Finally, the concentration of Torin2 utilised, failed to induce autophagy (Figure 7h).

To provide further evidence that autophagy controls c-MET phosphorylation via mTORC2, we investigated whether induction of mTORC2 activity could increase p-c-MET. To this end, we employed the mTORC1 inhibitor Rapamycin, which upregulates mTORC2 activity through inhibition of mTORC1mediated negative feedback loop. ${ }^{53-55}$ Autophagy-proficient and deficient HCT-116 cells were treated with Rapamycin and analysed at different time points. Rapamycin downregulated mTORC1 activity and increased pAKT S473. Notably, Rapamycin-mediated mTORC2 upregulation resulted in increased $\mathrm{p}-\mathrm{c}-\mathrm{MET}$ in autophagy-proficient but not in autophagy-deficient cells (Supplementary Figure 4). Collectively, our data suggest that basal autophagy regulates RTK activation in an mTORC2-dependent manner.

\section{Discussion}

Our study shows that autophagy is not a relevant target for pharmacological intervention upon EGFR inhibition when the $\mathrm{PI3K} / \mathrm{AKT} / \mathrm{mTORC} 1$ pathway is constitutively active, suggesting that concomitant EGFR and autophagy targeting in clinical settings would not be beneficial in KRAS- or PI3K-mutated $\mathrm{CRC}$ patients. However, a novel pathway is unravelled, whereby $\mathrm{mTORC} 1$-independent basal autophagy positively regulates RTK activation through mTORC2 signalling.
Specifically, we found that all CRC cell lines utilised exhibit basal autophagy, irrespective of their PI3K or KRAS mutational status. Although earlier studies suggested autophagy to be regulated in an $\mathrm{mTORC} 1$-independent manner, ${ }^{8-10}$ the role of basal autophagy in cancer remains elusive. We hypothesised that basal autophagy would not have a major degradative role, whereas it could affect cell signalling as previously suggested. ${ }^{45,46}$ Interestingly, we found that basal autophagy suppression reduces phosphorylation of several RTKs, such as c-MET, c-RET and Dtk; in most cases independently of KRAS mutational status. We focused on c-MET, as it is proposed to have an oncogenic role in CRC and has been characterised as a resistance mechanism to EGFR-targeted therapy. ${ }^{42,47}$ Levels of total c-MET remained stable following basal autophagy suppression suggesting that the decrease in phosphorylation levels of c-MET is not caused by reduced c-MET expression. In addition, our findings suggest that basal autophagy-mediated regulation of RTK phosphorylation is not attributed to a general metabolic control of tyrosine phosphorylation, as the latter was unaltered upon basal autophagy suppression. Therefore, we propose that an unconventional function of basal autophagy is responsible for the regulation of RTK phosphorylation and specifically $\mathrm{p}-\mathrm{c}-\mathrm{MET}$. We explored whether CRC basal autophagy could control signalling, as autophagosomes have been recently proposed to function as non-catabolic, cell signalling regulatory platforms. ${ }^{45} \mathrm{We}$ observed that autophagy suppression decreased mTORC2mediated regulation of AKT but did not alter mTORC1 activity, suggesting that autophagy-dependent regulation of mTORC2 is independent of mTORC1-negative feedback loop. ${ }^{53-55}$ The decrease in mTORC2 signalling occurred in cells with a constitutive PI3K pathway, suggesting that it was not caused by inhibition of RTK phosphorylation. Therefore, we investigated whether reduced mTORC2 signalling is responsible for the defect in RTK phosphorylation. Indeed, genetic inhibition of $\mathrm{mTORC2}$ as well as pharmacological inhibition of mTORC1/2 led to decreased C-MET phosphorylation in autophagyproficient but not autophagy-impaired cells. Vice versa, Rapamycin, which activates mTORC2, led to increased c-MET phosphorylation. Although we cannot exclude that decreased mTORC2 signalling in autophagy-impaired cells is partly due to inhibition of RTK signalling, our data suggest that autophagy positively mediates RTK phosphorylation via regulation of $\mathrm{mTORC2}$. $\mathrm{mTORC} 2$ has been described to

Figure 6 Autophagy suppression impairs mTORC2-mediated phosphorylation of AKT but not mTORC1 activation. Autophagy-proficient and compromised HCT-116 and DLD-1 KRAS WT and G13D isogenic cell lines as well as CaCo2 cells were treated with Dox for 5 days and total cell lysates were subjected to immunoblot analysis for the indicated proteins. (a-c) ATG7 knockdown regulates AKT phosphorylation at S473 residue in CRC cells. Total cell lysates of autophagy-proficient (shEGFP) and compromised (shATG7 E8) cells ((a) HCT-116, $n=4$; (b) DLD-1 $n=3$ and (c) CaCo2, $n=4$ ) were subjected to immunoblot analysis for pAKT S473 and total AKT levels. $\beta$-actin was used as loading control. Bar plots represent densitometric analysis of pAKT S473 relative to total AKT. The bars represent mean \pm S.D.; ns $=$ non-statistically significant, ${ }^{*} P<0.05$, ${ }^{\star *} P<0.01$ and ${ }^{* \star *} P<0.001$. Two-way ANOVA statistical analysis was used for (a) and (b) and unpaired Student's t-test for (c). (d-f) ATG7 knockdown does not regulate mTORC1 activation. Total cell lysates of autophagy-proficient (shEGFP) and compromised (shATG7 E8) cells ((d) HCT-116, $n=3$; (e) DLD-1, $n=3$ and (f) CaCo2, $n=3$ ) were subjected to immunoblot analysis for pS6 ribosomal protein S240/244 and total S6 ribosomal protein levels. $\beta$-actin and total AKT were used as loading controls. Bar plots represent densitometric analysis of pS6 ribosomal protein relative to total S6 ribosomal protein or loading control. The bars represent mean \pm S.D.; ns = non-statistically significant. Twoway ANOVA and unpaired Student's t-test statistical analysis was used for (d-e) and (f), respectively. (g-h) Autophagy-deficient HCT-116 cells confirm pAKT S473 and mTORC1 findings observed by downregulation of ATG7. Total cell lysates of autophagy-proficient (gRNA Ctrl) and deficient (gRNA ATG7 or ATG5) HCT-116 cells were subjected to immunoblot analysis for pAKT S473 and pS6 ribosomal protein S240/244 relative to total AKT and total S6 ribosomal protein levels, respectively. $\beta$-actin was used as loading control. Bar plots represent densitometric analysis of pAKT S473 relative to total AKT ( $\mathbf{g})$ and pS6 ribosomal protein relative to total S6 ribosomal protein (h). The bars represent mean \pm S.D. of $n=3$; ns $=$ non-statistically significant, ${ }^{* \star} P<0.001$. One-way ANOVA statistical analysis was used 
a

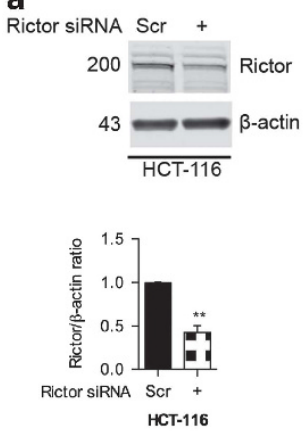

d gRNA Ctrl Ctrl ATG7 ATG7

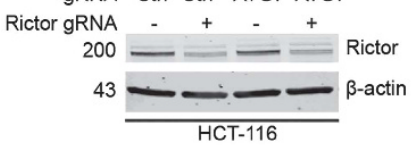

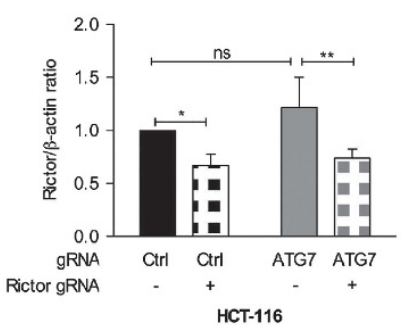

f

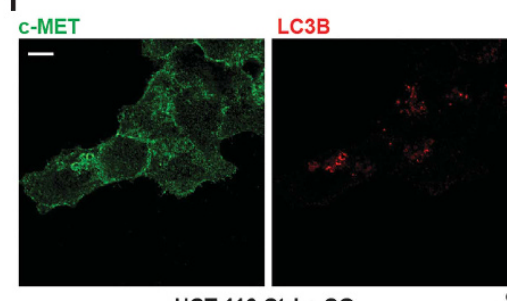

HCT-116 Ctrl + CQ

g

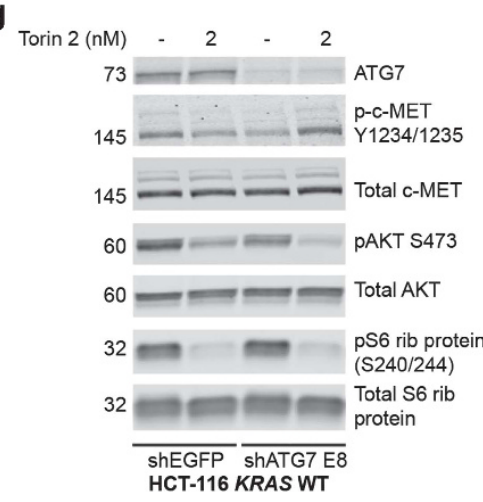

b

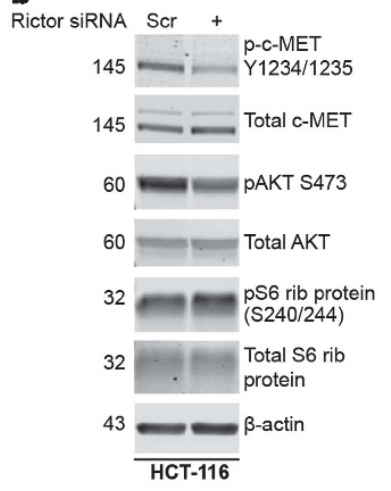

e gRNA Ctrl Ctrl ATG7 ATG7

Rictor gRNA - + - + p-c-MET

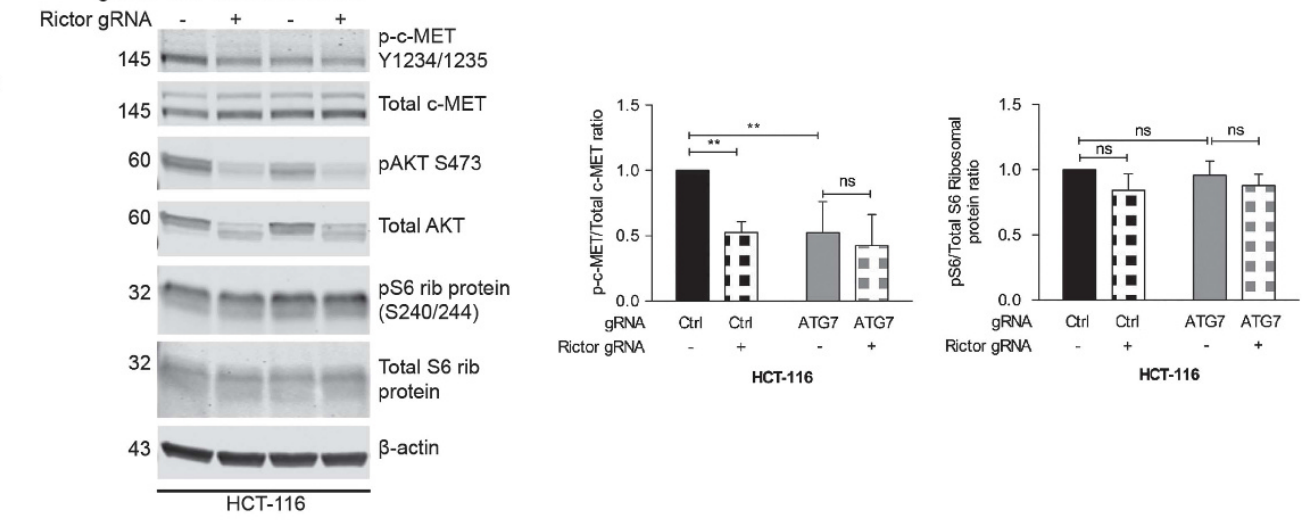

C

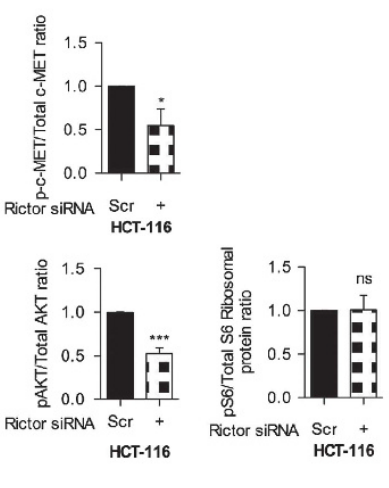

Rictor siRNA Scr + Scr + $\mathrm{CQ}(10 \mu \mathrm{M})$
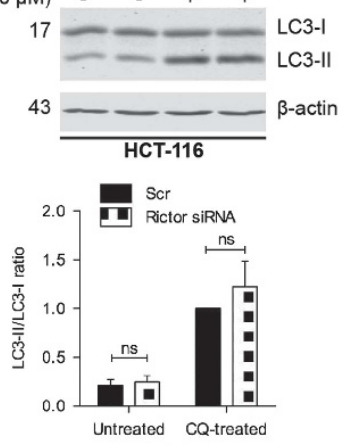

HCT-116
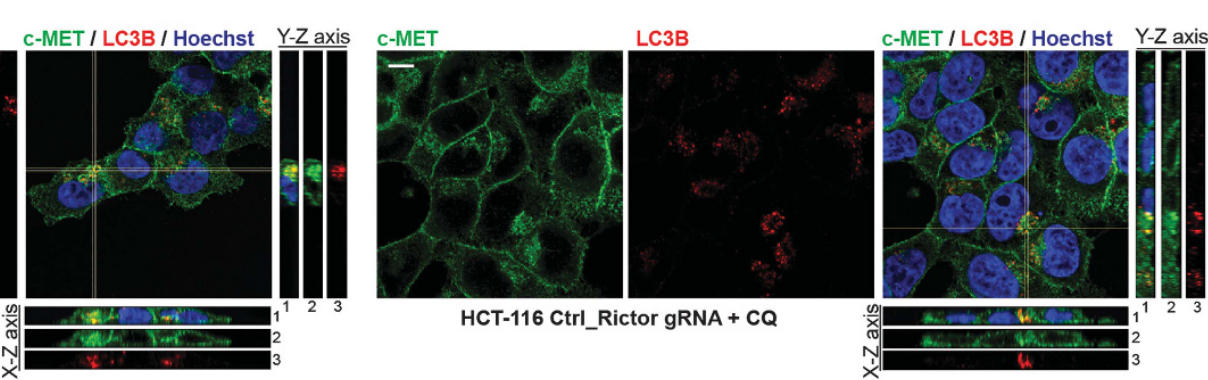

HCT-116 Ctrl_Rictor gRNA + CQ

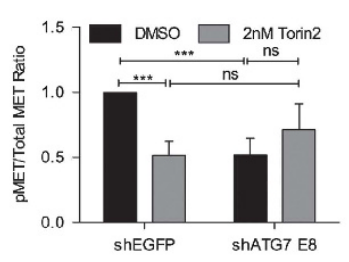

h

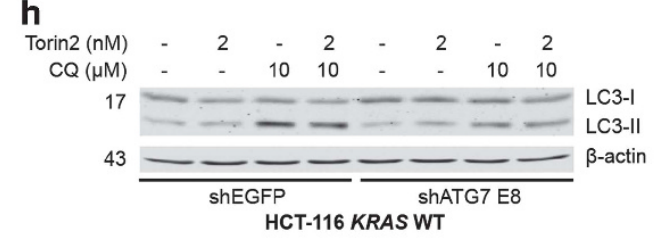

HCT-116 KRAS WT

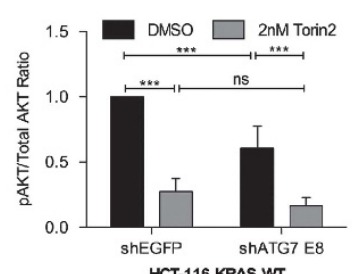

HCT-116 KRAS WT

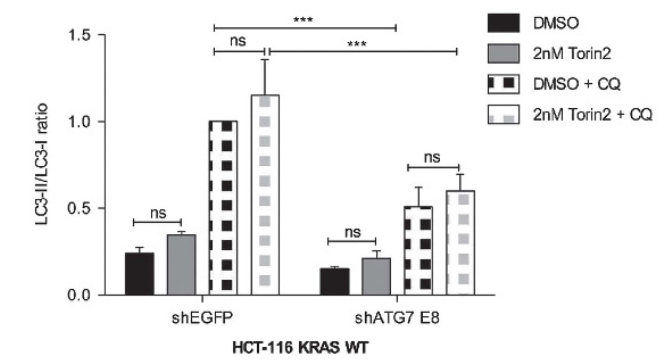


Figure 7 Basal autophagy-mediated regulation of c-MET phosphorylation involves mTORC2 signalling. (a) Immunoblot depicts levels of Rictor protein expression in HCT-116 cells treated with Scramble (Scr) and Rictor siRNA for 5 days. $\beta$-actin was used as loading control. Bar plots represent densitometric quantification of Rictor expression levels normalised to $\beta$-actin. The bars represent mean \pm S.D. of $n=3 ;{ }^{*} P<0.01$. Unpaired Student's $t$-test statistical analysis was used. (b) Immunoblot depicts reduced phosphorylation levels of c-MET and AKT but not S6 ribosomal protein following Rictor siRNA for 5 days. $\beta$-actin was used as loading control. Bar plots represent densitometric quantification of p-c-MET Y1234/1235, pAKT S473 and pS6 ribosomal protein relative to total c-MET, total AKT and total S6 ribosomal protein, respectively. The bars represent mean \pm S.D. of $n=4$; ns $=$ non-statistically significant; ${ }^{*} P<0.05$ and ${ }^{* \star *} P<0.001$. Unpaired Student's $t$-test statistical analysis was used. (c) Rictor knockdown does not affect levels of autophagy. Five days after Scr and Rictor-siRNA delivery, HCT-116 cells were treated $\pm 10 \mu \mathrm{M} \mathrm{CQ}$ for $6 \mathrm{~h}$ and total cell lysates were analysed using immunoblot for LC3B protein. $\beta$-actin was used as loading control. Bar plots represent densitometric analysis of LC3-II/LC3-I levels. The bars represent mean \pm S.D. of $n=4$; ns $=$ non-statistically significant. Two-way ANOVA statistical analysis was used. (d) Immunoblot depicts levels of Rictor protein expression in autophagy-proficient (gRNA Ctrl) and deficient (gRNA ATG7) HCT-116 cells transfected with Rictor gRNA. $\beta$-actin was used as loading control. Bar plots represent densitometric quantification of Rictor expression levels normalised to $\beta$-actin. The bars represent mean \pm S.D. of $n=4$; ns-non-statistically significant; ${ }^{*} P<0.05$; ${ }^{* *} P<0.01$. Two-way ANOVA statistical analysis was used. (e) Immunoblot depicts reduced phosphorylation levels of C-MET but not pS6 ribosomal protein following Rictor gRNA transfection. $\beta$-actin was used as loading control. Bar plots represent densitometric quantification of p-c-MET Y1234/1235 and pS6 ribosomal protein relative to total c-MET and total S6 ribosomal protein, respectively. The bars represent mean \pm S.D. of $n=4$; $\mathrm{ns}=$ non-statistically significant; ${ }^{* \star} P<0.01$. Two-way ANOVA statistical analysis was used. (f) Downregulation of Rictor does not affect c-MET internalisation nor its accumulation in intracellular LC3B-positive structures. Representative images from confocal sections of autophagy-proficient RictorWT (Ctrl) or KO (Ctrl_Rictor gRNA) HCT-116 cells treated with $10 \mu \mathrm{M} \mathrm{CQ}$ for $6 \mathrm{~h}$. Cells were fixed and stained for total c-MET (green), LC3B (red) and nucleus (Hoechst dye-blue). Scale bar corresponds to $5 \mu \mathrm{m}$. Orthogonal reconstruction of serial confocal slices is shown ( $Y-Z$ and $X-Z$ axis with 1: merge of total c-MET/LC3B/Hoechst; 2: total c-MET; 3: LC3B). Yellow lines on the confocal section indicate from where the orthogonal views were built. $(\mathbf{g}-\mathbf{h})$ mTOR kinase inhibition in autophagy-proficient cells reduces phosphorylation levels of c-MET without affecting autophagic flux. Autophagy-proficient (shEGFP) and compromised (shATG7 E8) HCT-116 KRASWT cells were treated with $10 \mathrm{ng} / \mathrm{ml}$ Dox for 5 days. At day 5 of Dox treatment, cells were treated with $2 \mathrm{nM}$ of the Torin2 inhibitor $\pm 10 \mu \mathrm{M} \mathrm{CQ}$ for $6 \mathrm{~h}$ and total cell lysates were subjected to immunoblotting for the indicated proteins. Bar plots represent densitometric quantification of p-c-MET Y1234/1235 relative to total c-MET protein and PAKT S473 relative to total AKT protein (g) and LC3-I//LC3-I levels (h). The bars represent mean \pm S.D. of $n=4(\mathbf{g})$ and $n=3(\mathbf{h}) ; n s=$ non-significant; ${ }^{* \star *} P<0.001$. Two-way ANOVA statistical analysis was used

directly regulate IGF-IR and IR phosphorylation in an mTOR kinase activity-dependent manner. ${ }^{53}$ It is therefore plausible that C-MET phosphorylation is regulated in an mTORC2 kinase-dependent manner. As no tight correlation was observed between increased levels of p-c-MET and pAKT S473 upon Rapamycin, autophagy may directly regulate c-MET activation through $\mathrm{mTORC} 2$ and only partly via AKT.

To investigate how autophagy regulates mTORC2 activity and c-MET phosphorylation, we studied the potential interaction between internalised C-MET and autophagic vesicles. Indeed, our findings show that c-MET partially colocalises with LC3B-positive structures intracellularly, whereas no colocalisation was observed with EGFR, consistent with the lack of effect on EGFR phosphorylation in the phospho-RTK arrays. In line with our results, a recent study showed that c-MET co-traffic with $\beta 1$-integrin to LC3B-positive compartments following HGF stimulation. However, this study failed to show that autophagy suppression affects c-MET phosphorylation, suggesting differences in the cancer cell model and/or experimental settings utilised. ${ }^{56}$ Interestingly, intracellular localisation of c-MET was not affected by autophagy suppression, suggesting that autophagic or autophagic-like vesicles do not regulate RTK internalisation but instead may represent signalling platforms regulating RTK phosphorylation. Accordingly, accumulation of autophagosomes caused by $\mathrm{CQ}$ treatment increased phosphorylation of c-MET, irrespectively of total c-MET levels, only in autophagy-proficient conditions. c-MET colocalised with LC3B vesicles negative for LAMP1, suggesting that this interaction is not the result of fusion of C-MET and LC3B vesicles with lysosomes. Furthermore, genetic downregulation of mTORC2 activity did not affect autophagy levels or interaction of endogenous C-MET with LC3B-positive intracellular structures. Overall, our data suggest that basal autophagy may regulate mTORC2 kinase activity at c-MET-positive autophagosomes, in turn affecting c-MET phosphorylation. The lack of Rictor and AKT antibodies suitable for IF did not allow us to study its intracellular localisation with respect to LC3B-positive vesicles. However, AKT activity regulation by mTORC2 in intracellular compartments such as lysosomes has been previously described. ${ }^{57}$ Furthermore, autophagy has been shown to affect activation of AKT and ERK, with the latter shown to directly associate with autophagosomes. ${ }^{45,46}$

This study establishes an unconventional role of basal autophagy in regulation of RTK activation and suggests a bidirectional relationship between autophagy and RTK signalling: on one hand RTKs inhibit autophagy via mTORC1, whereas on the other hand autophagy positively modulates RTK signalling via mTORC2 activation. Further work is needed to fully dissect the mechanisms by which autophagy controls RTK signalling and to investigate cell intrinsic and non-intrinsic functional implications of the autophagy/RTK pathway in CRC.

\section{Materials and Methods}

Chemical compounds and drugs. All chemical compounds and drugs were dissolved in an initial stock concentration and then in cell culture media to reach the final working concentration. Sterile conditions were followed throughout the preparation of all reagents. Fresh aliquots were used for each independent experiment. Chloroquine diphosphate salt (CQ) (\#C6628, Sigma (Dorset, UK)) was dissolved in sterile phosphate-buffered saline (PBS) and was used at a concentration of $10 \mu \mathrm{M}$. Doxycycline hyclate (Dox) powder (\#D9891, Sigma) was resuspended into sterile $\mathrm{H}_{2} \mathrm{O}$ and was used at the optimal working concentration of each CRC cell line (10 ng/ml for HCT-116; $100 \mathrm{ng} / \mathrm{ml}$ for DLD-1 and CaCo2 cells). Dox was used for stimulation of shRNA expression in the pLKO-Tet-On inducible CRC cell lines. Clinical-grade Cetuximab $(5 \mathrm{mg} / \mathrm{ml})$ was obtained from Merck Serono (Darmstadt, Germany) and was used at the indicated concentrations. All following drugs were dissolved in dimethyl sulfoxide (DMSO) (\#D2650, Sigma). AKT inhibitor vIll (\#124018, Calbiochem, Merck Millipore (Darmstadt, Germany)) was used at a $2 \mu \mathrm{M}$ concentration. Torin2 (\#475992, Calbiochem) was used at a concentration of $2 \mathrm{nM}$. Rapamycin (\#R5000, LC Laboratories (Woburn, MA, USA)) was used at a concentration of $10 \mathrm{nM}$. In all experiments wherein cells were treated with compounds diluted in DMSO, the corresponding untreated conditions were treated with equal concentrations of DMSO. 
Plasmids. A Dox-inducible system was used to knockdown ATG7 protein in CRC cells by using the Tet-pLKO-puro vector (Addgene plasmid \#21915, Addgene (Cambridge, MA, USA)), established by Dmitri Wiederschain lab. ${ }^{58}$ The CRISPR/ Cas9 system was used to delete ATG7 or ATG5 by using the lentiCRISPR vector (Addgene plasmid \#52961), established by the Zhang lab. ${ }^{59}$ The LAMP1_mRFP_FLAG vector (Addgene plasmid \# 34611) was used to overexpress LAMP1 lysosomal marker, established by the Sabatini DM lab. ${ }^{60}$ The Rictor CRISPR guide RNA (gRNA) 3 sequence, which was used for deleting Rictor, was provided already cloned in the pSpCas9BB-2A-GFP (PX458) vector by GenScript (Piscataway, NJ, USA). PX458 empty vector, which was used as a control for Rictor CRISPR gRNA experiments, was a kind gift from Dr. Scott Lowe (Memorial Sloan Kettering Cancer Center, USA).

Antibodies. Antibodies against human LC3B (1/1000; \#2775, Cell Signaling Technology (Leiden, The Netherlands)), ATG7 (1/500; \#2631, Cell Signaling Technology), $\beta$-actin (1/5000; \#A5441, Sigma), p62 (1/500; \#BML-PW9860, Enzo Life Sciences) and HGF (1/1000; \#ab83760, Abcam (Cambridge, UK)) were diluted in $5 \%$ milk (w/v) $1 \times$ PBS - $0.1 \%$ Tween-20 (Sigma) in the corresponding concentration and used for immunoblotting. Antibodies against human pAKT S473 (1/1000; \#4060, Cell Signaling Technology), total AKT (1/1000; \#9272, Cell Signaling Technology), total AKT (1/1000; \#2920, Cell Signaling Technology), ATG5 (1/1000; \#2630, Cell Signaling Technology), pS6 ribosomal protein S240/244 (1/1000; \#2215, Cell Signaling Technology), total S6 ribosomal protein (1/500; \#2317, Cell Signaling Technology), total IGF-IR beta (1/1000; \#3027, Cell Signaling Technology), total EGFR (1/500; \#2232, Cell Signaling Technology), p-c-MET Y1234/1235 (1/500; \#3077, Cell Signaling Technology), total c-MET (1/1000; \#8198, Cell Signaling Technology), Rictor (1/1000; \#2140, Cell Signaling Technology) and phosphotyrosine clone 4 G10 (1/500-1/1000; \#05321, Merck Millipore) were diluted in $5 \%$ BSA (w/v) $1 \times$ TBS $-0.1 \%$ Tween-20 (Sigma) in the corresponding concentration and used for immunoblotting. For immunoprecipitation (IP) studies, the antibodies against human total c-MET (\#8198, Cell Signaling Technology), total EGFR (\#4267, Cell Signaling Technology), total IGF-IR beta (\#3027, Cell Signaling Technology) and normal IgG (\#2729, Cell Signaling Technology) were used. For IF experiments, the antibodies against human LC3B (1/50; \#0231-100/LC3-5F10, nanoTools Antikörpertechnik GmbH \& Co. KG (Teningen, Germany)), total c-MET (1/150; \#8198, Cell Signaling Technology), total EGFR (1/50; \#4267, Cell Signaling Technology) and RFP (1/1000; \#5F8, ChromoTek GmbH (Planegg-Martinsried, Germany)) were used. Secondary antibodies used for immunoblotting were goat anti-rabbit IgG DyLight 800 (1/5000; \#35571, Thermo Fisher Scientific (Waltham, MA, USA)), goat anti-mouse IgG DyLight 680 (1/5000; \#35518, Thermo Fisher Scientific), ECL anti-rabbit IgG (1/5000; \#NA934V, GE Healthcare UK Limited (Hatfield, UK)) and ECL anti-mouse IgG (1/5000; \#NA931V, GE Healthcare UK Limited). Alexa Fluor conjugated secondary antibodies raised against the species of each primary antibody (1/1000; Invitrogen-Thermo Fisher Scientific) were used for IF experiments.

Cell culture. HCT-116 and DLD-1 KRAS WT and G13D isogenic cell lines were kindly provided by Professor Bert Vogelstein (Johns Hopkins University, USA). DiFi cells were kindly provided by Professor Alberto Bardelli (University of Torino, Torino, Italy). Cells were cultured in tissue culture dishes at $37^{\circ} \mathrm{C}$ in a humidified atmosphere of $5 \% \mathrm{CO}_{2}$. HCT-116, and DLD-1 cells were maintained in McCoy's $5 \mathrm{~A}$ medium containing $2 \mathrm{mM} \mathrm{L-glutamine.} \mathrm{CaC} 2$ cells were maintained in minimum essential medium (MEM) containing $2 \mathrm{mM} \mathrm{L-glutamine.} \mathrm{DiFi} \mathrm{cells} \mathrm{were} \mathrm{maintained}$ in Ham's F12 Nutrient mixture medium containing $1 \mathrm{mM}$ L-glutamine. HCT-116 cells knocked out (KO) for ATG7 or ATG5 and/or Rictor by using the CRISPR/Cas9 technology as well as the human embryonic kidney cell line HEK 293T were maintained in Dulbecco's Modified Eagle's medium (DMEM) supplemented with $4.5 \mathrm{~g} / \mathrm{l}$-Glucose and sodium pyruvate. All cell culture media were supplemented with 10\% fetal bovine serum (FBS, Thermo Fisher Scientific), and 1\% Penicillin/ Streptomycin (Gibco-Thermo Fisher Scientific). All inducible pLKO-Tet-On shRNAexpressing (shEGFP, shATG7 E8) stable cell lines were maintained in corresponding medium supplemented with 10\% Tet-Free Certified FBS (\#16000044, Lot number 1221032, Thermo Fisher Scientific). Cell number counting and cell viability examination was conducted using the Vi-Cell XR machine and software (Beckman Coulter, Indianapolis, IN, USA).

Transient transfection for siRNAs delivery. Silencer select Rictor siRNA (\#S226001, Thermo Fisher Scientific) and negative control (Scramble, \#4390843, Thermo Fisher Scientific) were used at a concentration of $10 \mathrm{nM}$ using
Lipofectamine RNAiMAX reagent (\#13778075, Thermo Fisher Scientific) in HCT-116 cells. Forward transfection protocol was followed according to the protocol of the manufacturer. Cells were harvested 5 days post transfection by scraping and protein knockdown was assessed using immunoblotting.

Lentivirus particle production. The calcium phosphate transfection method was used to generate lentivirus particles by transfecting HEK 293T cells with the corresponding plasmids. For pLKO-Tet-On shRNA autophagy-proficient (shEGFP) and compromised (shATG7 E8) as well as LAMP1_mRFP_FLAG lentivirus particle production, $6 \times 10^{6} \mathrm{HEK} 293 \mathrm{~T}$ cells were plated in $15 \mathrm{~cm}$ dishes containing $20 \mathrm{ml}$ complete DMEM medium and were let to adhere overnight at $37^{\circ}$ C. The following day, a triple co-transfection of HEK 293T cells with lentivirus packaging/envelope vectors and desired plasmid DNA was performed $(7.2 \mu \mathrm{g}$ of pCMV-VSV-G; $15.6 \mu \mathrm{g}$ pCMV-HIV-1; $24 \mu \mathrm{g}$ of desired lentivirus vector). For CRISPR/Cas9 -Ctrl/-ATG7/-ATG5 gRNAs lentivirus particle production, $1.5 \times 10^{6}$ HEK 293T cells were plated in $10 \mathrm{~cm}$ dishes containing $10 \mathrm{ml}$ complete DMEM medium and were let to adhere overnight at $37^{\circ} \mathrm{C}$. The following day, a triple cotransfection of HEK 293T cells with lentivirus packaging/envelope vectors and desired plasmid DNA was performed (7.5 $\mu \mathrm{g}$ of psPAX2; $4 \mu \mathrm{g}$ of VSV-G; $10 \mu \mathrm{g}$ of lentiCRISPR vectors encoding (Cas9 and Ctrl/ATG7/ATG5 gRNAs)).

DNA-mixture was diluted in sterile nuclease-free $\mathrm{H}_{2} \mathrm{O}$ containing $10 \%(\mathrm{v} / \mathrm{v}) 2.5 \mathrm{M}$ calcium chloride to a final volume of $1 \mathrm{ml}$. The DNA-calcium chloride mixture was thoroughly mixed and allowed to equilibrate at room temperature for $30 \mathrm{~min}$. In total, $37^{\circ} \mathrm{C}$ pre-warmed $2 \times$ HEPES pH 7.05 buffer $(280 \mathrm{mM} \mathrm{NaCl} ; 10 \mathrm{mM} \mathrm{KCl} ; 1.5 \mathrm{mM}$ $\mathrm{Na}_{2} \mathrm{HPO}_{4} ; 12 \mathrm{mM} \mathrm{D}(+)$-Glucose Monohydrate; $50 \mathrm{mM}$ HEPES) was added to the DNA-calcium chloride solution in a ratio 1:1 and the mixture was thoroughly mixed for $1 \mathrm{~min}$. DNA-calcium chloride-HEPES mixture was added dropwise to each $15 \mathrm{~cm}$ dish containing HEK 293T cells. Transfection medium was replaced with normal culture medium after $8 \mathrm{~h}$. Transfected HEK 293T cells were let to incubate for additional $48 \mathrm{~h}$, when supernatants containing viral particles collected.

Viral particles concentration by polyethylene glycol (PEG) precipitation was performed for pLKO-Tet-On shEGFP and shATG7 E8 as well as LAMP1_mRFP_FLAG lentivirus particles. In brief, supernatants containing lentivirus particles were centrifuged at $3000 \times g$ for 15 min to eliminate cells and cellular debris. Further cellular debris elimination was achieved by $0.45 \mu \mathrm{m}$ PVDF filtration of the supernatant. A total of $5 \times$ PEG pH $7.2(50 \mathrm{mM}$ PEG; $0.41 \mathrm{M} \mathrm{NaCl} ; 0.2 \%$ Tris $1 \mathrm{M}, \mathrm{pH} 7.5)$ solution was added to the supernatant containing the viral particles in a volume ratio $1: 4$ to concentrate the virus particles. Solution was refrigerated at $4{ }^{\circ} \mathrm{C}$ overnight. The next day the concentrated virus particles were pelleted down through centrifugation at $1500 \times \mathrm{g}$ for $30 \mathrm{~min}$ and PEG containing medium was discarded. Virus particle pellets were resuspended in sterile cold PBS in a volume ratio 50:1 and were aliquoted and stored at $-80^{\circ} \mathrm{C}$. Fresh concentrated virus particles aliquots were used in each independent viral transduction experiment. Tittering of virus was performed using antibiotic selection, as was previously described. ${ }^{58}$

For CRISPR/Cas9 - Ctrl/ATG7/ATG5 gRNAs lentivirus particle production, lentivirus-containing supernatant from HEK 293T cells was collected 48 and $72 \mathrm{~h}$ after transfection and filtered through a $0.45 \mu \mathrm{m}$ PTFE filter membrane. Lentiviruscontaining supernatant was added fresh to the target cells.

Generation of autophagy-compromised/-deficient CRC cell lines. Viral transduction was used to generate stable inducible-expressing pLKO-Tet-On shRNA autophagy-proficient (shEGFP) and compromised (shATG7 E8) CRC cell lines, autophagy-proficient (gRNA Ctrl) and deficient (gRNA ATG7 or ATG5) HCT-116 cells.

For pLKO-Tet-On shRNA-expressing CRC cell lines, $1.0 \times 10^{5}$ cells were plated in six-well plates and let to incubate overnight at $37^{\circ} \mathrm{C}$. Cells were transduced with the appropriate volume of the corresponding concentrated virus based on virus tittering at an $\mathrm{MOl}$ of 10 in media containing $5 \mu \mathrm{g} / \mathrm{ml}$ polybrene. Twenty-four hours later, viruscontaining medium was replaced by fresh complete medium and target cell lines were let to incubate for additional $24 \mathrm{~h}$. For CRISPR HCT-116 cells, $0.7 \times 10^{6}$ cells were plated in $10 \mathrm{~cm}$ dishes and let to incubate overnight at $37^{\circ} \mathrm{C}$. Cells were transduced with the lentivirus-containing supernatant (supernatant $48 \mathrm{~h}$ after transfection) from HEK $293 \mathrm{~T}$ cells supplemented with polybrene and let to incubate for $24 \mathrm{~h}$. The following day, fresh lentivirus-containing supernatant (supernatant $72 \mathrm{~h}$ after transfection) from HEK 293T cells was added to HCT-116 target cells for additional $24 \mathrm{~h}$.

Forty-eight hours after viral transduction, antibiotic selection of transduced cell populations was performed using puromycin selection for pLKO-Tet-On shRNA or CRISPR/Cas9 expressing cells $(0.5 \mu \mathrm{g} / \mathrm{ml}$ for HCT-116, $3 \mu \mathrm{g} / \mathrm{ml}$ for DLD-1 and 
$1.5 \mu \mathrm{g} / \mathrm{ml}$ for $\mathrm{CaCo} 2$ cells) and control cells. Antibiotic-containing medium was replaced every 2 days for at least a week in order to generate stable cell lines. All experiments were conducted in the absence of puromycin selection. The inducible downregulation of ATG7 protein was performed in the presence of Dox $(10 \mathrm{ng} / \mathrm{ml}$ for HCT-116; $100 \mathrm{ng} / \mathrm{ml}$ for DLD-1 and CaCo2 cells) for 5 days.

Generation of Rictor gRNA-expressing cells. Autophagy-proficient and deficient HCT-116 cells were transiently transfected either with pSpCas9BB-2 A-GFP (PX458) empty vector or -Rictor CRISPR guide RNA (gRNA) 3 expressing vector by using FuGENE transfection reagent (\#E2311, Promega Corp., Madison, WI, USA), in accordance with the instructions of the manufacturer. In brief, $1 \times 10^{6}$ cells were plated in $6 \mathrm{~cm}$ tissue culture dishes containing $5 \mathrm{ml}$ of complete medium and let to incubate overnight. Twenty-four hours later, $5 \mu \mathrm{g}$ of each desired vector was mixed with FuGENE transfection reagent, in a ratio of transfection reagent to DNA 3:1. Cells were incubated for $48 \mathrm{~h}$ and then subjected to cell sorting based on GFP expression in order to isolate the transfected cell population for each condition.

Total cell protein extraction. A total of $2.5-4 \times 10^{5}$ of $\mathrm{CRC}$ cells (depending on each CRC cell line) were plated in $6 \mathrm{~cm}$ tissue culture dishes and let to adhere for $\sim 48 \mathrm{~h}$ at $37^{\circ} \mathrm{C}$ until $\sim 70 \%$ of confluence was reached. Drug treatment was applied under sterile conditions for the indicated incubation time and total cell protein extraction followed. Cell culture medium was removed and adhered cells were washed once with $1 \times$ PBS. 100-150 $\mu$ l of RIPA Lysis Buffer (20 mM Tris pH 7.4; $150 \mathrm{mM} \mathrm{NaCl} ; 1 \mathrm{mM}$ EDTA pH 8; $1 \mathrm{mM}$ EGTA pH 8; 0.5\% (w/v) sodium deoxycholate; $0.1 \%$ (v/v) sodium dodecyl sulphate (SDS); $1 \%$ (v/v) Nonidet P-40) or Non-Denaturing Lysis Buffer (20 mM Tris pH 7.4; 137 mM NaCl; 2 mM EDTA pH 8; $1 \%(\mathrm{v} / \mathrm{v})$ Nonidet P-40) supplemented with protease inhibitors $(10 \mu \mathrm{g} / \mathrm{ml}$ of each Pepstatin A (\#P5318, Sigma), Aprotinin (\#A6279, Sigma) and Leupeptin (\#L8511, Sigma) or $1 \times$ of the protease inhibitor cocktail (\#11697498001; Roche, Basel, Switzerland)) and phosphatase inhibitors ( $1 \mathrm{mM} \mathrm{Na}_{3} \mathrm{VO}_{4}$ (\#S6508, Sigma); $50 \mathrm{mM}$ $\mathrm{NaF}$ (\#201154, Sigma)) was added to the cells on ice. Cell scraping was used to harvest cells from the culture dishes and cell lysates were transferred to microcentrifuge tubes. Cell lysates were incubated on ice for $30 \mathrm{~min}$ and then centrifuged at $13200 \mathrm{rpm}$ for $15 \mathrm{~min}$ at $4{ }^{\circ} \mathrm{C}$. Supernatants containing total cell protein extracts were transferred to new microcentrifuge tubes and kept on ice as long as the total cell protein concentration of extracts was quantified. For determination of total cell protein concentration, the BCA protein assay kit (\#23227, Thermo Fisher Scientific) or Bradford assay (\#500-0006, BioRad (Hertfordshire, UK)) were used according to instructions of the manufacturer. Following total cell protein concentration quantification, $5 \times$ protein loading buffer (10\% (w/v) SDS; $50 \%$ (w/v) glycerol; $0.125 \%$ (w/v) bromophenol blue; $250 \mathrm{mM}$ Tris pH 6.8; $2 \mathrm{mM}$ 2-mercaptoethanol) was added to cell lysates in a ratio 1:4 in order to yield a final concentration of $1 \times$ protein loading buffer to the cell extracts. Total cell extracts were boiled at $95^{\circ} \mathrm{C}$ for $5 \mathrm{~min}$.

Immunoblotting. Equal concentration of total cell extracts (30-50 $\mu \mathrm{g})$ were separated in $8 \%, 10 \%, 15 \%$ SDS-polyacrylamide gel electrophoresis (SDS-PAGE) or Criterion TGX Stain-Free Precast Gels (BioRad) as required and transferred for 2 and half hours onto nitrocellulose membrane in a wet blotter. $1 \times$ Running Buffer (0.186 M glycine; $0.02 \mathrm{M}$ Trisma Base; $0.15 \%$ (v/v) SDS) was used for protein electrophoresis and $1 \times$ Transfer Buffer (0.186 M Glycine; 0.02 M Trisma Base; 20\% $(\mathrm{v} / \mathrm{v})$ Methanol) was used for protein transfer. Efficiency of protein transfer onto nitrocellulose membranes was examined by shortly incubating membranes in Ponceau S (Sigma) solution that reversibly removed by $1 \times$ PBS $-0.1 \%$ Tween-20 or $1 \times$ TBS $-0.1 \%$ Tween-20 washes. Nitrocellulose membranes were blocked in $5 \%$ BSA (w/v) $1 \times$ TBS $-0.1 \%$ Tween-20 for phosphorylated studies and in $5 \%$ milk (w/v) $1 \times$ PBS $-0.1 \%$ Tween-20 for all other studies with $1 \mathrm{~h}$ incubation time. Immunodetection performed by incubating membranes with primary antibody overnight at $4{ }^{\circ} \mathrm{C}$ and with the corresponding secondary antibody diluted in $5 \%$ milk (w/v) $1 \times$ PBS $-0.1 \%$ Tween-20 for $1 \mathrm{~h}$. Protein expression was detected on medical X-Ray films using the Enhanced Chemiluminescence System (ECL) when HRP-conjugated secondary antibodies used. The Odyssey imaging System scanner (LI-COR Biotechnology-UK Ltd, Cambridge, UK) was used for detection of protein expression when fluorescent dye-conjugated secondary antibodies were used. LI-COR Odyssey software or Fiji (Image-J, NIH, MD, USA) software was used for densitometric analysis of protein bands detected either via LI-COR Odyssey Imaging System scanner or ECL, respectively.
Immunoprecipitation. Lyophilised protein A Sepharose beads (\#71-7090OOAF, GE Healthcare UK Limited) were hydrated in distilled $\mathrm{H}_{2} \mathrm{O}$ based on the instructions of the manufacturer and followed coupling of the protein A Sepharose beads with the antibodies used in IP studies. In brief, the Sepharose protein A slurry was gently mixed by vortexing and $10 \mu \mathrm{l}$ of beads were washed twice with nondenaturing lysis buffer by intermediate centrifugations of $20 \mathrm{~s}$ at $13200 \mathrm{rpm}$. Followed coupling of beads with the required volume of antibody in $300 \mu \mathrm{l}$ of nondenaturing lysis buffer via rotation at $4{ }^{\circ} \mathrm{C}$ for $4 \mathrm{~h}$. Antibody-Sepharose $\mathrm{A}$ coupled beads were washed four times in non-denaturing lysis buffer containing protease and phosphatase inhibitors with intermediate centrifugation steps as abovementioned. IP was performed via incubating $500-1000 \mu \mathrm{g}$ of total cell protein extracts (into non-denaturing lysis buffer containing phosphatase and protease inhibitors) with $10 \mu \mathrm{l}$ antibody-Sepharose A coupled beads in a total volume of $1000 \mu \mathrm{l}$ with rotating for $3 \mathrm{~h}$ at $4^{\circ} \mathrm{C}$. Then beads were washed four times with $1000 \mu \mathrm{l}$ non-denaturing lysis buffer containing phosphatase and protease inhibitors followed by centrifugation for $20 \mathrm{~s}$ at $13200 \mathrm{rpm}$. The pellet was resuspended in $50 \mu \mathrm{l}$ of $1 \times$ protein loading buffer, incubated at $95{ }^{\circ} \mathrm{C}$ for $5 \mathrm{~min}$ and centrifuged at $13200 \mathrm{rpm}$ for $1 \mathrm{~min}$. The supernatant containing the immunoprecipitated proteins was then analysed using immunoblotting.

Phospho-RTK array. The human phospho-RTK array (\#ARY001B (R\&D Systems, Abingdon, UK)) was used for the determination of changes in phosphorylation of RTKs between autophagy-proficient and compromised samples. The array was conducted with the specific reagents provided and based on the instructions of the manufacturer. In brief, $1.5-2 \times 10^{6}$ autophagy-proficient or compromised cells (depending on the cell line used) were plated in $10 \mathrm{~cm}$ tissue culture dishes at day 3 of Dox treatment and let to adhere for another $48 \mathrm{~h}$ at $37^{\circ} \mathrm{C}$ in the presence of Dox. Then cells were lysed using Lysis Buffer 17 supplemented with protease and phosphatase inhibitors and protein quantification of total cell extracts was conducted using Bradford assay. In total, $1500 \mu \mathrm{g}$ of total cell extracts was diluted into array buffer 1 to reach a volume of $1.5 \mathrm{ml}$ and samples of each autophagy-proficient or compromised condition were applied onto the nitrocellulose membrane with the RTK-captured antibodies. Followed overnight incubation at $4{ }^{\circ} \mathrm{C}$ on a rocking platform shaker and the next day nitrocellulose membranes were washed and incubated with a pan anti-phospho-tyrosine antibody conjugated to HRP in a dilution 1:5000 for $2 \mathrm{~h}$ at room temperature. The phosphorylated tyrosines on RTKs were detected by chemilluminescence using X-ray Films and multiple exposure times $(20 \mathrm{~s}-10 \mathrm{~min})$ were used to detect the majority of RTKs. Nitrocellulose membranes incubated with autophagy-proficient or compromised lysates were placed into the same autoradiography cassette and developed concomitantly to allow comparison between conditions. For densitometric analysis of phospho-RTK array results, X-ray films were scanned in high-resolution (1200 dpi) and the GS-800 Calibrated Densitometer (BioRad) was used to quantify the intensity of each independent RTK spot. Numerical results were analysed by determining the average signal (pixel intensity) of the pair of duplicate spots presenting each RTK and followed by subtraction of an averaged background signal for each RTK independently. Differences in RTK phosphorylation were determined by comparing phosphorylation of RTKs between autophagy-proficient and compromised cells.

Human HGF ELISA. A total of $2 \times 10^{6}$ autophagy-proficient or deficient (ATG7 and ATG5 KO) HCT-116 cells were plated in $10 \mathrm{~cm}$ dishes (10 ml of medium) and let to incubate for $48 \mathrm{~h}$ under nutrient/growth factor-replete conditions. Conditioned medium was collected from cells, centrifuged to remove cellular debris and human HGF (hHGF) protein concentration was quantified using the hHGF DuoSet ELISA kit (\#DY294, R\&D Systems), according to the manufacturer's protocol.

SRB cell proliferation/viability assay. Using the SRB colorimetric assay, cell proliferation/viability was assessed in autophagy-proficient and compromised HCT-116 and DLD-1 KRAS WT and G13D cells, upon nutrient/growth factor-replete conditions. Autophagy-proficient (shEGFP) and autophagy-compromised (shATG7 E8) CRC cells were treated with Dox for 5 days to efficiently downregulate ATG7 protein. At day 5 of Dox treatment, 2000 cells/200 $\mu$ l of medium (supplemented with Dox) were plated in each well of flat 96-well plates. Cell density was measured from day 1-6 and day 1-7 for HCT-116 and DLD-1 cells, respectively. In brief, media was aspirated from the wells and cells were fixed in 10\% (w/v) of Trichloroacetic acid for $20 \mathrm{~min}$ at $4{ }^{\circ} \mathrm{C}$. Cells were stained in $0.4 \%$ (w/v) SRB solution for $20 \mathrm{~min}$ at room temperature. Traces of the unbound dye were removed by washing cells five times with $1 \%(\mathrm{w} / \mathrm{v})$ Trichloroacetic acid and the plates air-dried overnight. The dye was 
solubilised with $10 \mathrm{mM}$ Tris base (pH 10.5) for 30 min at room temperature and absorbance was measured at $540 \mathrm{~nm}$.

Anchorage-independent cell growth assay. Anchorage-independent cell growth assay was used to examine differences in cell growth between autophagyproficient and deficient (ATG7 and ATG5 KO) HCT-116 cells. In brief, 6\% (w/v) low melting point agarose (\#16520, Invitrogen) was prepared in distilled $\mathrm{H}_{2} \mathrm{O}$ and mixture was autoclaved. The following day, $6 \%$ agarose was solubilised via microwaving until uniformly in solution and was diluted in cell culture medium to reach a concentration of $2 \%$. Two percentage agarose was thoroughly mixed by pipetting and was further diluted in cell culture medium to reach a concentration of $0.6 \%$. The remaining $2 \%$ agarose was kept at $40{ }^{\circ} \mathrm{C}$ waterbath for use in later steps of the procedure. In total, $2 \mathrm{ml}$ of $0.6 \%$ agarose was plated in six-well culture dishes and let to polymerase at room temperature to create the agarose bottom layer. In the meantime, cells were trypsinised, counted and 500 cells were transferred to tubes containing the appropriate volume of medium to further dilute $2 \%$ agarose in a concentration of $0.35 \%$. In total, $2 \mathrm{ml}$ of $0.35 \%$ agarose containing cells was placed onto the $0.6 \%$ agarose bottom layer. The top layer of agarose containing cells was shortly incubated at room temperature to enable polymerisation and then placed at $37^{\circ} \mathrm{C}$ in a humidified atmosphere of $5 \% \mathrm{CO}_{2}$ incubator. The next day, $2 \mathrm{ml}$ of medium was added on top of the $0.35 \%$ agarose layer and followed regular medium changes every 3 days for a duration of 21 days. For visualisation of cell colonies $145 \mu \mathrm{g} / \mathrm{ml}$ of Iodonitrotetrazolium Chloride dye was added in each well and cells were let to incubate for another $24 \mathrm{~h}$ at $37^{\circ} \mathrm{C}$. Images were acquired using the Image Quant LAS 4000 machine and automatic quantification of cell colonies was conducted by using the ImageQuant software by following instructions of the manufacturer.

Cell migration assay. Cell migration assay was performed using BD Falcon cell culture inserts (\#353097, BD Biosciences). A total of $5 \times 10^{4}$ cells in nutrient/ growth factor-replete cell culture medium were seeded at migration chambers of a 24-well plate and allowed to migrate for $60 \mathrm{~h}$ through 8-micron pore Polyethylene Terephthalate (PET) membrane. As a chemoattractant, nutrient/growth factor-replete cell culture medium supplemented with $50 \mathrm{ng} / \mathrm{ml} \mathrm{hHGF}$ was used at the bottom of each well. Non-migrated cells were removed from the top of the PET membranes by gently cleaning with cotton swabs. Migrated cells were fixed in $100 \%$ methanol for 2 mins and stained with 1:5000 Hoescht for 30 mins at room temperature. To quantify the number of migrated cells, the surface of each well was photographed under inverted fluorescence microscope at $\times 10$ magnification. The total number of cells per condition was counted by using the Cell profiler program.

Immunofluorescence. A total of $6 \times 10^{4} \mathrm{HCT}-116$ cells were plated on sterile glass coverslips in 24-well plates and let to adhere for $48 \mathrm{~h}$ at $37^{\circ} \mathrm{C}$. Cells were treated with $10 \mu \mathrm{M} \mathrm{CQ}$ for $6 \mathrm{~h}$. Cells were fixed with $4 \%$ PFA for $15 \mathrm{~min}$, followed incubation in $100 \%$ methanol for $10 \mathrm{~min}$ in $-20^{\circ} \mathrm{C}$ and finally three washes in $1 \times$ PBS (5 min each). Fixed cells were blocked in blocking buffer (5\% BSA in $1 \times$ PBS supplemented with $0.3 \%$ Triton-X100) for $1 \mathrm{~h}$ at room temperature and were stained with the corresponding primary antibody overnight at $4{ }^{\circ} \mathrm{C}$. After primary antibody incubation, cells were washed three times with $1 \times$ PBS $-0.1 \%$ Tween-20 to remove traces of unspecifically bound antibody and followed incubation in dark with secondary fluorescent-conjugated antibodies at room temperature for $1 \mathrm{~h}$. Traces of secondary antibody were removed by washing three times with $1 \times$ PBS $-0.1 \%$ Tween-20. Nuclear staining was performed via incubating cells with Hoechst dye in a dilution 1:5000 in PBS for 30 min. Coverslips were mounted on microscope slides, let to dry and stored at $4{ }^{\circ} \mathrm{C}$. Images were acquired using a Zeiss LSM 700 or LSM 880 (Carl Zeiss Microscopy Ltd, Cambridge, UK) confocal microscope using $\times 63$ objective/1.4 numerical aperture. Z-stack images thickness was set to $0.4 \mu \mathrm{m}$ and images in each experiment were acquired at same settings and exposure times. Post-acquisition brightness adjustments were identical between images of the same experiment and performed using Imaris software.

For triple colocalisation analysis of c-MET/LC3B/LAMP1 markers, the Imaris software was used. In brief, confocal z-stacks data sets were rendered into $3 \mathrm{D}$ view images and software's built-in tools were used to generate c-MET, LC3B and LAMP1 spots. Spots for C-MET, LC3B and LAMP1 staining were generated based on the mean intensity of each channel and the diameter size of each independent c-MET, LC3B and LAMP1 pixel. Pixel diameter was measured by calculating the average diameter size of $\sim 70$ particles in single sections (LC3B diameter $=0.508 \mu \mathrm{m}$; C-MET diameter $=0.419 \mu \mathrm{m}$; LAMP1 diameter $=0.49 \mu \mathrm{m})$. Next, colocalisation analysis was performed using the colocalisation spots function, which assesses colocalisation based on the distance between spots. Colocalised spots were defined as two spots that have distance less than equal to the average diameter of the assessing spots. The pool of c-MET that colocalises with LAMP1 was distinguished from the pool of $c$-MET that does not colocalise with LAMP1 (Colocalised c-MET-LAMP1 spots distance $\leq 0.4545 \mu \mathrm{m})$. Then the pool of c-MET that did not colocalise with LAMP1 was assessed for colocalisation with LC3B spots (Colocalised C-MET-LC3B spots distance $\leq 0.4635 \mu \mathrm{m})$.

Determination of KRAS and PIK3CA mutational status. A total of $2 \times 10^{6}$ CRC cells were harvested by trypsinisation, pelleted down and subjected to RNA extraction by using the RNeasy Plus Mini Kit (\#74134, Qiagen Ltd, (Manchester, UK)). The procedure conducted based on the instructions of the manufacturer. Total RNA was eluted in $30 \mu \mathrm{l}$ RNase-free $\mathrm{H}_{2} \mathrm{O}$. The high-capacity cDNA reverse transcription kit (\#4368814, Thermo Fisher Scientific) was used to retrotranscribe $1 \mu \mathrm{g}$ of RNA isolated from CRC cells based on the instructions of the manufacturer. In brief, reverse-transcription PCR reaction was performed in a total volume of $20 \mu$ l containing RNA and $2 \times$ RT mastermix (10x RT buffer; $25 \times$ dNTP Mix; 10x RT random primers; multiscribe reverse transcriptase; RNA inhibitors; nuclease-free $\mathrm{H}_{2} \mathrm{O}$ ) in a 1:1 ratio. The conditions of reverse-transcription PCR were $25^{\circ} \mathrm{C}$ for $10 \mathrm{~min}, 37^{\circ} \mathrm{C}$ for $120 \mathrm{~min}$ and $85^{\circ} \mathrm{C}$ for $5 \mathrm{~min}$.

The newly synthesised CDNA was used with each of the following primer pairs for KRAS and PIK3CA mutational status determination using PCR.

\section{KRAS_Exon1-2 forward primer: 5'-AGGCCTGCTGAAAATGACTGAA-3' KRAS_Exon3 reverse primer: 5'-GGTCCCTCATTGCACTGTACTCC-3' PIK3CA_Exon15-16 forward primer: 5'-ATGATTTACGGCAAGATATGC-3' PIK3CA_Exon20 reverse primer: 5'-TCAGTTCAATGCATGCTGTTT-3' \\ PIK3CA_Exon4-5 forward primer: 5'-AAGATCTATGTTCGAACAGGT-3' \\ PIK3CA Exon11-10 reverse primer: 5'-ACATCTGGGCTACTTCATCTC-3'}

PCR reactions were performed in a total volume of $50 \mu \mathrm{l}$, containing $5 \mu \mathrm{M}$ of each forward and reverse primers, $46 \mu \mathrm{l}$ PCR Master Mix ( $\mathrm{MgCl}_{2}$ buffer; dNTPs; nucleasefree $\mathrm{H}_{2} \mathrm{O}$ ) with 1 Unit of FastStart Taq DNA Polymerase (Roche). The conditions of PCR reactions were for KRAS fragments: 35 cycles of $95^{\circ} \mathrm{C}$ for $1 \mathrm{~min}, 62.1^{\circ} \mathrm{C}$ for $45 \mathrm{~s}$ and $72{ }^{\circ} \mathrm{C}$ for $45 \mathrm{~s}$ with an initial denaturation cycle of $95^{\circ} \mathrm{C}$ for $5 \mathrm{~min}$ and a final extension cycle of $70{ }^{\circ} \mathrm{C}$ for $7 \mathrm{~min}$; and PIK3CA fragments: 35 cycles of $95^{\circ} \mathrm{C}$ for $1 \mathrm{~min}, 60^{\circ} \mathrm{C}$ for $45 \mathrm{~s}$ and $72^{\circ} \mathrm{C}$ for 1 min with an initial denaturation cycle of $95^{\circ} \mathrm{C}$ for $5 \mathrm{~min}$ and a final extension cycle of $72{ }^{\circ} \mathrm{C}$ for $10 \mathrm{~min}$. Fractionation of PCR products was performed by electrophoresis in 1-1.5\% Agarose (\#A9539, Sigma)/TAE gel containing ethidium bromide. DNA was mixed with $5 \times$ DNA Loading Buffer (100 mM Tris pH 8; $10 \mathrm{mM}$ EDTA pH 8; $50 \%$ Glycerol; $0.5 \%$ (w/v) bromophenol blue) and electrophoresed at $100 \mathrm{~V}$ for $\sim 30 \mathrm{~min}$. DNA bands were visualised under ultraviolet light. Purification of DNA fragments from Agarose/TAE gel was performed by GeneJet Gel Extraction kit (\#K0691, Thermo Fisher Scientific) following the instructions of the manufacturer. Sequencing of PCR amplified fragments was performed in the UCL Cl sequencing facility by using the appropriate primers. Sequencing results were visualised using Finch TV software and were further analysed by using the EMBOSS Pairwise Alignment Algorithm from the EMBL-EBI Database (http://www.ebi.ac.uk/Tools/emboss/align)).

Cloning of shRNA oligos to pLKO-Tet-On vector. To generate shRNA pLKO-Tet-On expressing plasmids against ATG7 protein, single-stranded oligos encoding the desired shRNA sequence were designed based on previously published shATG7 sequences. ${ }^{18}$ ATG7 single-stranded oligo sequences were incorporated with cloning overhangs and loop sequence. ATG7 single-stranded oligos first were annealed and then cloned into the inducible lentiviral pLKO-Tet-On vector by following the previously described protocols. ${ }^{58}$ For the annealing of singlestranded oligos, $11.25 \mu \mathrm{l}$ of each forward and reverse oligo (100 $\mu \mathrm{M})$ were mixed with $2.5 \mu \mathrm{l}$ of $10 x$ annealing buffer $(1 \mathrm{M} \mathrm{NaCl} ; 100 \mathrm{mM}$ Tris- $\mathrm{HCl}, \mathrm{pH} 7.4)$ and a PCR programme was used to perform the reaction. The conditions of the PCR programme used are: $10 \mathrm{~min}$ at $98^{\circ} \mathrm{C}, 5 \mathrm{~min}$ at $95^{\circ} \mathrm{C}, 5 \mathrm{~min}$ at $90^{\circ} \mathrm{C}, 5 \mathrm{~min}$ at $88^{\circ} \mathrm{C}, 5 \mathrm{~min}$ at $85^{\circ} \mathrm{C}, 5 \mathrm{~min}$ at $80^{\circ} \mathrm{C}, 5 \mathrm{~min}$ at $78^{\circ} \mathrm{C}, 5 \mathrm{~min}$ at $75^{\circ} \mathrm{C}, 5$ min at $70^{\circ} \mathrm{C}$, 5 min at $68^{\circ} \mathrm{C}, 5 \mathrm{~min}$ at $65^{\circ} \mathrm{C}, 5 \mathrm{~min}$ at $60^{\circ} \mathrm{C}, 5 \mathrm{~min}$ at $58^{\circ} \mathrm{C}, 5 \mathrm{~min}$ at $55^{\circ} \mathrm{C}, 5 \mathrm{~min}$ at $50^{\circ} \mathrm{C}, 5 \mathrm{~min}$ at $45^{\circ} \mathrm{C}, 5 \mathrm{~min}$ at $40^{\circ} \mathrm{C}, 10 \mathrm{~min}$ at $37^{\circ} \mathrm{C}$ and cooling down to $4^{\circ} \mathrm{C}$. The annealed oligo mixture was diluted in $0.5 \times$ of annealing buffer in a ratio 1:400 and ligated to the cloning sites of pLKO-Tet-On vector created by Agel (Promega) IEcoRI (Roche) digestion in Multicore buffer (Promega). The reaction was incubated at $37^{\circ} \mathrm{C}$ for 1 and half hours and the restriction digestion products were visualised on $1 \%$ Agarose / TAE gel. Followed purification of the digested pLKO-Tet-On vector from Agarose/TAE gel by following the instructions of the manufacturer (GeneJet Gel Extraction kit; \#K0691; Thermo Fisher Scientific). Ligation reaction was performed in a total volume of $10 \mu \mathrm{l}$, containing double-stranded oligos, the digested 
pLKO-Tet-On vector, $2 \times$ Rapid Ligase buffer (\#C671B, Promega) and T4 DNA ligase (\#M180B, Promega). Ligation mixture was incubated at room temperature for $15 \mathrm{~min}$ and transformation of ligated products in Stbl3 cells followed. Bacteria colonies were grown to enable purification of plasmid DNA using the JetStar 2.0 Plasmid Purification Kit (Genomed, Löhne, Germany) according to the instructions of the manufacturer. Verification of the inserted oligos was conducted by sequencing.

Cloning of guide RNA sequences to lentiCRISPR vector. The target guide RNA sequence against human ATG7 or ATG5 was designed based on the Zhang Lab GeCKO website http://www.genome-engineering.org/gecko/. In addition, the CRISPR design tool software http://crispr.mit.edu/ was used for the identification of suitable target sites for guide RNA sequence design against ATG7 or ATG5. For targeting ATG7, the exon 2 coding sequence: 5'-GAAGCTGAACGAG TATCGGC-3' was used. For targeting ATG5, the exon 3 coding sequence: 5'-AAGAGTAAGTTATTTGACGT-3' was used. For control (Ctrl), the gRNA sequence 5'-GTAGCGAACGTGTCCGGCGT-3' was used, generated by Wang et al..$^{61}$ The abovementioned oligo sequences integrated with specific overhangs for cloning were used.

To clone the Ctrl and ATG7 or ATG5 gRNA sequences, $5 \mu \mathrm{g}$ of the lentiCRISPR vector was enzymatically digested with BsmBI (NEB) using Buffer 3.1 (NEB) for $2 \mathrm{~h}$ at $37^{\circ} \mathrm{C} .10 \mu \mathrm{M}$ of each single-stranded forward and reverse -gRNA oligo was phosphorylated using T4 polynucleotide Kinase (Cambio) at $37^{\circ} \mathrm{C}$ for $30 \mathrm{~min}$ (based on the instructions of the manufacturer) and then annealed by heating at $95^{\circ} \mathrm{C}$ for $5 \mathrm{~min}$ and cooling down to $25^{\circ} \mathrm{C}$ at $5{ }^{\circ} \mathrm{C} / \mathrm{min}$. The annealed gRNA oligos were diluted in a $1 / 200$ concentration using $\mathrm{ddH}_{2} \mathrm{O}$ and ligated into $50 \mathrm{ng}$ gel purified vector (QIAquick Gel Extraction Kit; \#28704, Qiagen). For ligation reaction, the Rapid DNA Ligation kit (\#11 635379 001, Roche) was used at room temperature for 15 min according to the instructions of the manufacturer. Followed transformation of ligated products in Stbl3 cells. Bacteria colonies were grown and purification of plasmid DNA from mini-cultures was performed. Verification of gRNA cloning was conducted by sequencing using the LKO forward primer: 5'-GACTATCATATGCTTACCGT-3'. Positive clones were amplified in large-volume bacteria cultures and plasmid DNA was isolated for long-term storage and use.

Statistical analysis. Means of at least three independent experiments unless otherwise stated were statistically analysed using GraphPad Prism v5 (GraphPad Software, Inc, La Jolla, CA, USA). Determination of statistical significance in singlecomparisons was performed using two-tailed unpaired Student's $t$-test with Welch's correction and in multiple means comparisons using one-way or two-way ANOVA followed by the Bonferroni post-test.

\section{Conflict of Interest}

The authors declare no conflict of interest.

Acknowledgements. We thank $\mathrm{Dr}$ Pablo Rodriguez-Viciana (University College London, UK), Dr Ivana Bjedov (University College London, UK), Professor Bart Vanhaesebroeck (University College London, UK), Dr Benoit Bilanges (University College London, UK), Professor Clare Futter (University College London, UK), Professor Bert Vogelstein (Johns Hopkins University, USA), Professor Alberto Bardelli (University of Torino, Italy) for reagents. Special thanks also to all members of PS and DH laboratories and the CRUK UCL Centre Core Services and the UCL Scientific Services. AL was recipient of a PhD studentship award from the UCL Grand Challenges. DH was supported by the Cancer Research UK Programme Grant (C2259/A16569). PS is head of the Brain Tumour Charity-funded Samantha Dickson Brain Cancer Unit.

1. Feng Y, He D, Yao Z, Klionsky DJ. The machinery of macroautophagy. Cell Res 2014; 24: 24-41.

2. Musiwaro $P$, Smith $M$, Manifava $M$, Walker $S A$, Ktistakis NT. Characteristics and requirements of basal autophagy in HEK 293 cells. Autophagy 2013; 9: 1407-1417.

3. Kroemer G, Marino G, Levine B. Autophagy and the integrated stress response. Mol Cell 2010; 40: 280-293.

4. Amaravadi RK, Lippincott-Schwartz J, Yin XM, Weiss WA, Takebe N, Timmer W et al. Principles and current strategies for targeting autophagy for cancer treatment. Clin Cancer Res 2011; 17: 654-666.
5. Galluzzi L, Pietrocola F, Bravo-San Pedro JM, Amaravadi RK, Baehrecke EH, Cecconi F et al. Autophagy in malignant transformation and cancer progression. EMBO J 2015; 34 856-880.

6. Russell RC, Yuan HX, Guan KL. Autophagy regulation by nutrient signaling. Cell Res 2014; 24: $42-57$.

7. Kim Y-M, Jung Chang H, Seo M, Kim Eun K, Park J-M, Bae Sun S et al. mTORC1 phosphorylates UVRAG to negatively regulate autophagosome and endosome maturation. Mol Cell 2015; 57: 207-218.

8. Wei Y, Zou Z, Becker N, Anderson M, Sumpter R, Xiao G et al. EGFR-mediated beclin 1 phosphorylation in autophagy suppression, tumor progression, and tumor chemoresistance. Cell 2013; 154: 1269-1284.

9. Tan X, Thapa N, Sun Y, Anderson Richard A. A kinase-independent role for EGF receptor in autophagy initiation. Cell 2015; 160: 145-160.

10. Sarkar S. Regulation of autophagy by mTOR-dependent and mTOR-independent pathways: autophagy dysfunction in neurodegenerative diseases and therapeutic application of autophagy enhancers. Biochem Soc Trans 2013; 41: 1103-1130.

11. Takamura A, Komatsu M, Hara T, Sakamoto A, Kishi C, Waguri S et al. Autophagy-deficient mice develop multiple liver tumors. Genes Dev 2011; 25: 795-800.

12. Qu X, Yu J, Bhagat G, Furuya N, Hibshoosh $\mathrm{H}$, Troxel A et al. Promotion of tumorigenesis by heterozygous disruption of the beclin 1 autophagy gene. J Clin Invest 2003; 112: 1809-1820.

13. Mathew R, Kongara S, Beaudoin B, Karp CM, Bray K, Degenhardt K et al. Autophagy suppresses tumor progression by limiting chromosomal instability. Genes Dev 2007; 21 1367-1381.

14. Mathew R, Karp CM, Beaudoin B, Vuong N, Chen G, Chen HY et al. Autophagy suppresses tumorigenesis through elimination of p62. Cell 2009; 137: 1062-1075.

15. Liang $\mathrm{XH}$, Jackson $\mathrm{S}$, Seaman $\mathrm{M}$, Brown $\mathrm{K}$, Kempkes $\mathrm{B}$, Hibshoosh $\mathrm{H}$ et al. Induction of autophagy and inhibition of tumorigenesis by beclin 1. Nature 1999; 402 : 672-676.

16. Karantza-Wadsworth V, Patel S, Kravchuk O, Chen G, Mathew R, Jin S et al. Autophagy mitigates metabolic stress and genome damage in mammary tumorigenesis. Genes Dev 2007; 21: 1621-1635.

17. Bellodi C, Lidonnici MR, Hamilton A, Helgason GV, Soliera AR, Ronchetti M et al. Targeting autophagy potentiates tyrosine kinase inhibitor-induced cell death in Philadelphia chromosome-positive cells, including primary CML stem cells. J Clin Invest 2009; 119: $1109-1123$

18. Galavotti S, Bartesaghi S, Faccenda D, Shaked-Rabi M, Sanzone S, McEvoy A et al. The autophagy-associated factors DRAM1 and p62 regulate cell migration and invasion in glioblastoma stem cells. Oncogene 2013; 32: 699-712.

19. Guo JY, Karsli-Uzunbas G, Mathew R, Aisner SC, Kamphorst JJ, Strohecker AM et al. Autophagy suppresses progression of K-ras-induced lung tumors to oncocytomas and maintains lipid homeostasis. Genes Dev 2013; 27: 1447-1461.

20. Levy J, Cacheux W, Bara MA, L'Hermitte A, Lepage P, Fraudeau M et al. Intestinal inhibition of Atg7 prevents tumour initiation through a microbiome-influenced immune response and suppresses tumour growth. Nat Cell Biol 2015; 17: 1062-1073.

21. Rao S, Tortola L, Perlot T, Wirnsberger G, Novatchkova M, Nitsch R et al. A dual role for autophagy in a murine model of lung cancer. Nat Commun 2014; 5: 3056.

22. Rosenfeldt MT, O'Prey J, Morton JP, Nixon C, MacKay G, Mrowinska A et al. p53 status determines the role of autophagy in pancreatic tumour development. Nature 2013; 504: 296-300

23. Strohecker AM, Guo JY, Karsli-Uzunbas G, Price SM, Chen GJ, Mathew R et al. Autophagy sustains mitochondrial glutamine metabolism and growth of BrafV600E-driven lung tumors. Cancer Discov 2013; 3: 1272-1285

24. Strohecker AM, White E. Autophagy promotes BrafV600E-driven lung tumorigenesis by preserving mitochondrial metabolism. Autophagy 2014; 10: 384-385

25. Yang A, Rajeshkumar NV, Wang X, Yabuuchi S, Alexander BM, Chu GC et al. Autophagy is critical for pancreatic tumor growth and progression in tumors with p53 alterations. Cancer Discov 2014; 4: 905-913.

26. Tang MC, Wu MY, Hwang MH, Chang YT, Huang HJ, Lin AM et al. Chloroquine enhances gefitinib cytotoxicity in gefitinib-resistant nonsmall cell lung cancer cells. PloS One 2015; 10 : e0119135.

27. Li Y-y, Lam S-k, Mak JC-w, Zheng C-y, Ho JC-m. Erlotinib-induced autophagy in epidermal growth factor receptor mutated non-small cell lung cancer. Lung Cancer 2013; 81: 354-361.

28. Li X, Lu Y, Pan T, Fan Z. Roles of autophagy in cetuximab-mediated cancer therapy against EGFR. Autophagy 2010; 6: 1066-1077.

29. Li X, Fan Z. The epidermal growth factor receptor antibody cetuximab induces autophagy in cancer cells by downregulating HIF-1alpha and Bcl-2 and activating the beclin 1/hVps34 complex. Cancer Res 2010; 70: 5942-5952.

30. Han W, Pan H, Chen Y, Sun J, Wang Y, Li J et al. EGFR tyrosine kinase inhibitors activate autophagy as a cytoprotective response in human lung cancer cells. PloS One 2011; 6 : e18691

31. Eimer S, Belaud-Rotureau MA, Airiau K, Jeanneteau M, Laharanne $\mathrm{E}$, Veron $\mathrm{N}$ et al. Autophagy inhibition cooperates with erlotinib to induce glioblastoma cell death. Cancer Biol Ther 2011; 11: 1017-1027.

32. Dragowska WH, Weppler SA, Wang JC, Wong LY, Kapanen Al, Rawii JS et al. Induction of autophagy is an early response to gefitinib and a potential therapeutic target in breast cancer. PloS One 2013; 8: e76503. 
33. Humbert M, Medová M, Aebersold DM, Blaukat A, Bladt F, Fey MF et al. Protective autophagy is involved in resistance towards MET inhibitors in human gastric adenocarcinoma cells. Biochem Biophys Res Commun 2013; 431: 264-269.

34. Takeuchi H, Bilchik A, Saha S, Turner R, Wiese D, Tanaka M et al. c-MET expression level in primary colon cancer: a predictor of tumor invasion and lymph node metastases. Clin Cancer Res 2003; 9: 1480-1488.

35. Radinsky R, Risin S, Fan D, Dong Z, Bielenberg D, Bucana CD et al. Level and function of epidermal growth factor receptor predict the metastatic potential of human colon carcinoma cells. Clin Cancer Res 1995; 1: 19-31.

36. Sato K, Tsuchihara K, Fujii S, Sugiyama M, Goya T, Atomi Y et al. Autophagy is activated in colorectal cancer cells and contributes to the tolerance to nutrient deprivation. Cancer Res 2007; 67: 9677-9684

37. Wasan H, Meade AM, Adams R, Wilson R, Pugh C, Fisher D et al. Intermittent chemotherapy plus either intermittent or continuous cetuximab for first-line treatment of patients with KRAS wild-type advanced colorectal cancer (COIN-B): a randomised phase 2 trial. Lancet Oncol 2014; 15: 631-639.

38. Troiani T, Napolitano S, Della Corte CM, Martini G, Martinelli E, Morgillo F et al. Therapeutic value of EGFR inhibition in CRC and NSCLC: 15 years of clinical evidence. ESMO Open 2016; 1: e000088.

39. Taieb J, Tabernero J, Mini E, Subtil F, Folprecht G, Van Laethem JL et al. Oxaliplatin, fluorouracil, and leucovorin with or without cetuximab in patients with resected stage III colon cancer (PETACC-8): an open-label, randomised phase 3 trial. Lancet Oncol 2014; 15: 862-873.

40. Price TJ, Peeters M, Kim TW, Li J, Cascinu S, Ruff $P$ et al. Panitumumab versus cetuximab in patients with chemotherapy-refractory wild-type KRAS exon 2 metastatic colorectal cancer (ASPECCT): a randomised, multicentre, open-label, non-inferiority phase 3 study. Lancet Oncol 2014; 15: 569-579.

41. De Roock W, De Vriendt V, Normanno N, Ciardiello F, Tejpar S. KRAS, BRAF, PIK3CA, and PTEN mutations: implications for targeted therapies in metastatic colorectal cancer. Lancet Oncol 2011; 12: 594-603.

42. Misale S, Di Nicolantonio F, Sartore-Bianchi A, Siena S, Bardelli A. Resistance to anti-EGFR therapy in colorectal cancer: from heterogeneity to convergent evolution. Cancer Discov 2014; 4: 1269-1280.

43. Klionsky DJ, Abdelmohsen K, Abe A, Abedin MJ, Abeliovich H, Acevedo Arozena A et al. Guidelines for the use and interpretation of assays for monitoring autophagy (3rd edn) Autophagy 2016; 12: 1-222.

44. Komatsu M, Kageyama S, Ichimura Y. p62/SQSTM1/A170: physiology and pathology. Pharmacol Res 2012; 66: 457-462.

45. Martinez-Lopez N, Athonvarangkul D, Mishall P, Sahu S, Singh R. Autophagy proteins regulate ERK phosphorylation. Nat Commun 2013; 4: 2799.
46. Bernard M, Dieudé M, Yang B, Hamelin K, Underwood K, Hébert M-J. Autophagy fosters myofibroblast differentiation through MTORC2 activation and downstream upregulation of CTGF. Autophagy 2014; 10: 2193-2207.

47. Bardelli A, Corso S, Bertotti A, Hobor S, Valtorta E, Siravegna G et al. Amplification of the MET receptor drives resistance to anti-EGFR therapies in colorectal cancer. Cancer Discov 2013; 3: 658-673.

48. Kammula US, Kuntz EJ, Francone TD, Zeng Z, Shia J, Landmann RG et al. Molecular co-expression of the c-Met oncogene and hepatocyte growth factor in primary colon cancer predicts tumor stage and clinical outcome. Cancer Lett 2007; 248: 219-228.

49. Trusolino L, Bertotti A, Comoglio PM. MET signalling: principles and functions in development, organ regeneration and cancer. Nat Rev Mol Cell Biol 2010; 11: 834-848.

50. Sandilands E, Serrels B, Wilkinson S, Frame MC. Src-dependent autophagic degradation of Ret in FAK-signalling-defective cancer cells. EMBO Rep 2012; 13: 733-740.

51. Jones S, Cunningham DL, Rappoport JZ, Heath JK. The non-receptor tyrosine kinase Ack1 regulates the fate of activated EGFR by inducing trafficking to the p62/NBR1 preautophagosome. J Cell Sci 2014; 127: 994-1006.

52. Humphrey SJ, Yang G, Yang P, Fazakerley DJ, Stockli J, Yang JY et al. Dynamic adipocyte phosphoproteome reveals that Akt directly regulates mTORC2. Cell Metab 2013; 17: 1009-1020.

53. Yin Y, Hua H, Li M, Liu S, Kong Q, Shao T et al. mTORC2 promotes type I insulin-like growth factor receptor and insulin receptor activation through the tyrosine kinase activity of mTOR. Cell Res 2016; 26: 46-65.

54. Xie J, Proud CG. Signaling crosstalk between the mTOR complexes. Translation 2014; 2: e28174.

55. Liu P, Gan W, Inuzuka H, Lazorchak AS, Gao D, Arojo O et al. Sin1 phosphorylation impairs mTORC2 complex integrity and inhibits downstream Akt signalling to suppress tumorigenesis. Nat Cell Biol 2013; 15: 1340-1350.

56. Barrow-McGee R, Kishi N, Joffre C, Menard L, Hervieu A, Bakhouche BA et al. Beta 1-integrin-c-Met cooperation reveals an inside-in survival signalling on autophagy-related endomembranes. Nat Commun 2016; 7: 11942.

57. Arias E, Koga H, Diaz A, Mocholi E, Patel B, Cuervo Ana M. Lysosomal mTORC2/PHLPP1/ Akt regulate chaperone-mediated autophagy. Mol Cell 59: 270-284.

58. Wiederschain D, Wee S, Chen L, Loo A, Yang G, Huang A et al. Single-vector inducible lentiviral RNAi system for oncology target validation. Cell Cycle 2009; 8: 498-504.

59. Sanjana NE, Shalem O, Zhang F. Improved vectors and genome-wide libraries for CRISPR screening. Nat Methods 2014; 11: 783-784.

60. Zoncu R, Bar-Peled L, Efeyan A, Wang S, Sancak Y, Sabatini DM. mTORC1 senses lysosomal amino acids through an inside-out mechanism that requires the vacuolar $\mathrm{H}$ (+)-ATPase. Science 2011; 334: 678-683.

61. Wang T, Wei JJ, Sabatini DM, Lander ES. Genetic screens in human cells using the CRISPR-Cas9 system. Science 2014; 343: 80-84.

Supplementary Information accompanies this paper on Cell Death and Differentiation website (http://www.nature.com/cdd) 